\title{
Evaluation and fitting of a numerical model for reinforced concrete thin walls through experimental results of monotonic and cyclic loading tests
}

\author{
Roger Ortega $^{a *}$ (D) , Carlos Naranjo ${ }^{b}$ (D) , Pedro Torres ${ }^{a}$ (D) Carlos Madera $^{a}$ (D), Johannio Marulanda ${ }^{a}$ (D), \\ Peter Thomson $^{a}$ (D) , Gilberto Areiza ${ }^{a}$ iD
}

a School of Civil Engineering and Geomatics, Universidad del Valle. Ciudad universitaria Meléndez, Calle 13 \# 100-00 Cali, Edificio E48, Cali, Colombia. E-mail: ortega.roger@correounivalle.edu.co,pedro.torres@correounivalle.edu.co, carlos.madera@correounivalle.edu.co, Johannio.marulanda@correounivalle.edu.co,peter.thomson@correounivalle.edu.co,gilberto.areiza@correounivalle.edu.co ${ }^{b}$ Department of Civil Engineering, Universidad Libre de Pereira. Belmonte, Avenida Las Américas, Pereira, Colombia. E-mail: carlos.naranjot@unilibre.edu.co

*Corresponding author

https://doi.org/10.1590/1679-78256575

\begin{abstract}
Reinforced concrete thin walls buildings have become one of the most common alternatives for housing construction in Colombia. However, some studies on this system have reported that walls have a limited deformation capacity and may suffer brittle failures. In this paper, a numerical model developed in OpenSees was used to represent the behavior of thin and slender reinforced concrete walls. The model was evaluated and fitted with the experimental response of two representative walls of this type of construction in high seismic hazard zone, in addition to the results of cyclic tests of other investigations with walls of similar characteristics. The experimental response of the walls indicated that, despite reaching a moderate deformation capacity, for the $1 \%$ drift limit, the level of damage was severe and lost $77 \%$ and $67 \%$ of their initial stiffness, respectively, which confirms that their performance is limited and provides a warning that the design practices may be insufficient. The numerical simulation correlated well with the experimental response in terms of displacement capacity, strength, and hysteric behavior.
\end{abstract}

\section{Keywords}

Reinforced concrete thin walls, numerical models, OpenSees, deformation capacity, lateral load tests.

\section{Graphical Abstract}

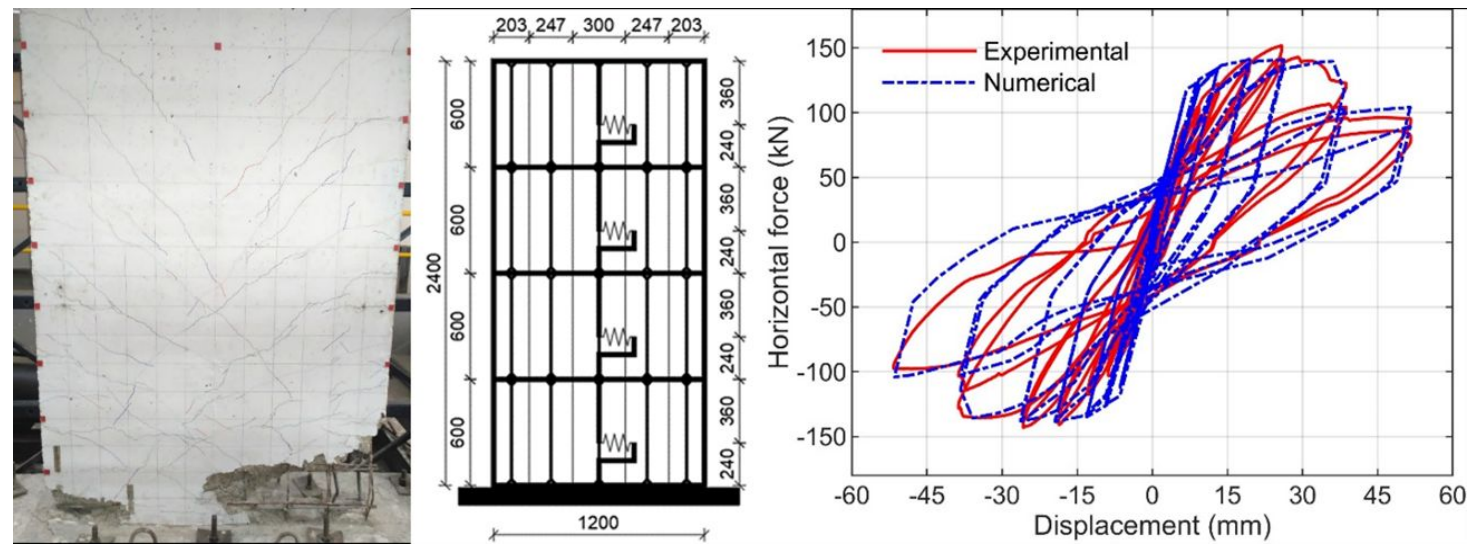




\section{INTRODUCTION}

In several Latin American countries, particularly Colombia, the industrialized system of housing construction, which consists of reinforced concrete thin walls (RCTW) buildings that can be efficiently constructed based on the type of formwork and materials used, has become extremely popular. Compared to traditional construction systems, the industrialized system is characterized by reduced labor and material requirements. The system uses construction processes that are simple and easy to replicate on each story of a building. The walls and slab of an entire story are often monolithically constructed on a single day. These buildings typically have between 4 and 15 stories and are characterized by the use of thin walls, with thicknesses $\left(t_{w}\right)$ between 80 and $150 \mathrm{~mm}$ and electro-welded reinforcements in the web of the walls arranged in a single curtain in most cases. The typical web reinforcement ratio of both longitudinal and transverse reinforcements is $0.25 \%$, which is the minimum value specified in the Colombian Code for EarthquakeResistant Construction, NSR 10 (AIS, 2010). At the ends of the walls, boundary elements are required in some cases; these elements have the same thickness as the wall web, and their longitudinal reinforcement is composed of ductile conventional steel supported by hoops or crossties.

The features of this system provide great advantages from a performance standpoint compared to other construction methods and make it an efficient alternative for housing construction. However, after earthquakes in Chile (2010) and New Zealand (2011), several studies have reported that even for thicker walls, the performance of these structural elements may be limited due to their low inelastic deformation capacity, low energy dissipation capacity, outof-plane instability and the possibility of brittle failure, among other aspects (Wallace et al., 2012), (Alarcon et al., 2014), (Gonzales \& López-Almansa, 2012), (Rosso et al., 2016).

In Colombia, even the RCTW buildings built in high seismic risk areas have high slenderness ratios (typical height/thickness ratio is 24) and single layers of reinforcement, which makes them susceptible to out-of-plane instability (Almeida et al., 2016), (Parra \& Moehle, 2014); the thin thicknesses do not guarantee suitable concrete confinement at the wall ends subjected to high demands of flexural compression (Arteta et al., 2014) and cause construction difficulties in the concrete pouring process. Additionally, the use of low ductility electro-welded meshes can limit the displacement capacity of the walls (Carrillo \& Alcocer, 2012). The implementation of these characteristics in Colombia has been possible as the design criteria in the building codes NSR-98 and NSR-10 (AIS, 2010), do not establish a minimum wall thickness. The structural behavior of this thin wall system is under discussion because the Colombian regulations for structural concrete are based on previous versions of $\mathrm{ACl} 318$ (ACl Committee 318, 2008), which established design provisions for the traditional structural system of reinforced concrete walls, in which the thicknesses are larger and favor the conditions for reinforcement detailing, concrete confinement and out-of-plane stability.

The above findings and the experimental results of thicker walls have generated interest in the evaluation of the performance of walls with the typical design and construction features in Colombia. Among the first studies conducted in Colombia is that of Blandón et al. (2015) at the School of Engineering of Antioquia, who subjected three walls with a rectangular cross-section and a thickness of $80 \mathrm{~mm}$ to cyclic lateral loading with different axial load ratios (ALR) and reported a limited rotation capacity, a high degree of cracking and a significant loss of lateral stiffness for low lateral drift levels. In Switzerland, Rosso et al. (2016) tested two T-shaped walls with a thickness of $80 \mathrm{~mm}$ and ALR values of $4.3 \%$ and $3.3 \%$, which is representative of this type of construction in Colombia. The first wall was subjected to a unidirectional (in-plane) lateral load, and the second was subjected to a bidirectional (in-plane, out-of-plane) lateral load. Both walls experienced significant out-of-plane displacements for lateral drifts of approximately $0.75 \%$, and the damage caused by out-of-plane deformations ultimately triggered a brittle failure due to concrete crushing and reinforcement buckling at the free web edge (no flange) of the wall. The results of this test confirmed the importance of the maximum tensile strain attained in the previous cycle as the parameter that triggers out-of-plane instability. (ALR $=N / f^{\prime}{ }^{\prime} \cdot A_{g}$, where $N$ is the axial load, $f^{\prime}{ }_{c}$ is the compressive strength of the concrete, and $A_{g}$ is the gross area of the cross-section of the wall).

Subsequently, Blandon et al. (2018) experimentally tested four walls with a combination of axial load, shear force, and moment gradient. The $100 \mathrm{~mm}$ thick walls were T-shaped, and one of them was built with a small eccentric edge at the end opposite to the flange, forming a pseudo-I-shaped cross-section. The ALR of these walls was less than $5 \%$. The results showed that the deformation capacity was low at less than $1.43 \%$, which corresponds to the story-drift limit for cracked sections (NSR-10) and suggests that this type of wall does not meet the performance required by NSR-10. The walls showed a rapid and high stiffness degradation, and the failure was characterized by fracture of the reinforcement due to damage concentration in the foundation-wall joint and an adherence failure of the reinforcement. Studies of walls with conditions similar to those in Colombia have also been developed in Perú (Quiroz et al., 2013), (Gonzales \& LópezAlmansa, 2012).

These findings help to understand the behavior of RCTW buildings. However, the experimental data remain limited, and because the response of these constructions to seismic events (e.g., design earthquake) is unknown, it is necessary 
to gather experimental evidence for different test conditions to establish a better characterization of the structural system. This paper presents the results of the first stage of a research project on the performance of RCTW buildings. In this first stage, a numerical model was developed in OpenSees, which was evaluated and fitted with the experimental response of two walls representative of this construction system in high seismic hazard zone. The model was also calibrated with the experimental results of walls with similar characteristics from well-known bibliographic references. This model is proposed as a valid tool for representing the hysteretic behavior of thin and slender reinforced concrete walls.

\section{EXPERIMENTAL DESIGN}

This research tested two full-scale reinforced concrete walls. The first wall, denominated M0R10, was tested with a monotonic lateral load and a $2 \%$ axial load ratio. The second test was implemented for wall M1R10, which corresponds to a cyclic lateral loading test with a $9 \%$ axial load ratio. The results of these tests were used to calibrate the proposed numerical model. Dimensions, materials, steel reinforcement ratios, type and configuration of the reinforcement, the axial load ratios, and the shear-span ratio were selected according to the statistical analysis of a database of 121 buildings located in the cities of Cali and Popayán, Colombia (Ortega et al., 2019).

The database corresponds to residential buildings between 4 and 14 stories (Figure 1). These constructions were designed prior to Resolution 0017 of December 2017 (Comisión Asesora Permanente para el Régimen de Construcciones Sismo Resistentes, 2017), which emphasized compliance with limitations on the thickness and detailing of boundary elements in Colombia. The average density of walls of the first story is $2.0 \%$ and $2.5 \%$ for the longitudinal and transverse directions of the building, respectively. Wall density is defined as the ratio between the wall section area and the floor plan area of a story and is calculated for each principal direction of the building. Typical wall thicknesses and clear height are $100 \mathrm{~mm}$ and $2400 \mathrm{~mm}$. In most cases, the nominal concrete strength is $21 \mathrm{MPa}$ and the walls are reinforced with a single curtain of electro-welded wire mesh. The typical web reinforcement ratio, $\rho_{w}$, varies between $0.12 \%$ and $0.7 \%$, with a typical value of $0.25 \%$ (NSR-10 minimum requirement), and the longitudinal reinforcement ratio in the wall edges varies between $0.5 \%$ and $4 \%$. The study of the database contemplated the analysis of other variables, such as the characteristics of the boundary elements, the aspect ratios of the walls, the detailing of the reinforcement, and the structural properties of the buildings, among others.

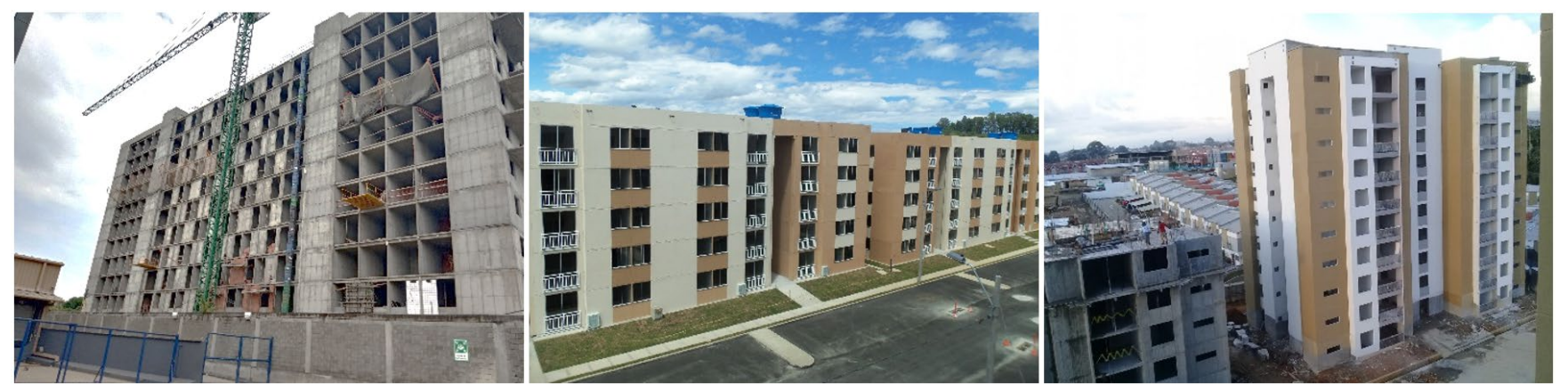

Figure 1. Reinforced concrete thin walls buildings.

\subsection{Characteristics of the test walls}

The length $\left(I_{w}\right)$, height $\left(h_{w}\right)$, and thickness $\left(t_{w}\right)$ of the walls were $1200 \mathrm{~mm}, 2400 \mathrm{~mm}$, and $100 \mathrm{~mm}$, respectively (Figure 2). The height was defined as the height of a typical story, the selected thickness was the most common in medium height buildings, and the length was established according to the laboratory conditions. Table 1 summarizes the characteristics of the test walls. During construction, an attempt was made to reproduce the construction process commonly used for this structural system.

Table 1 Characteristics of the test walls.

\begin{tabular}{|c|c|c|c|c|c|c|c|c|}
\hline \multirow[t]{2}{*}{ Wall } & $t_{w}$ & $I_{w}$ & $h_{w}$ & $\mathbf{f}_{c \text { design }}$ & $f_{c \exp }^{\prime}$ & web reinforcement $\left(\rho_{w}\right)$ & Reinforcement at the ends $\left(\rho_{b}\right)$ & $s / d_{b}$ \\
\hline & $(\mathrm{mm})$ & $(\mathrm{mm})$ & $(\mathrm{mm})$ & (MPa) & (MPa) & & & \\
\hline MOR10 & 100 & 1200 & 2400 & 21 & 24.7 & Bars No. 2 c/ 125 mm (0.25\%) & 2 bars No. $4 .(1.46 \%)$ & 11.8 \\
\hline M1R10 & 100 & 1200 & 2400 & 21 & 24.7 & Mesh $\varnothing 7 \mathrm{~mm} \mathrm{c/} 150$ mm. (0.26\%) & 2 bars No. $4 .(1.46 \%)$ & 11.8 \\
\hline
\end{tabular}


The MOR10 wall was reinforced with No. 2 bars (6.35 mm diameter) spaced every $125 \mathrm{~mm}$, in both directions, arranged in a single layer $\left(\rho_{\mathrm{w}}=0.25 \%\right)$. The M1R10 wall was reinforced with a layer of electro-welded wire mesh of $7 \mathrm{~mm}$ diameter with a spacing of $150 \mathrm{~mm}$ in both directions $\left(\rho_{w}=0.26 \%\right)$. The longitudinal reinforcement ratio at the ends, for both walls, $\rho_{b}$, was $1.46 \%$ and consisted of two No. 4 bars (12.7 mm diameter) supported by No. 2 reinforcement hooks spaced every $150 \mathrm{~mm}\left(S / d_{b}=11.8\right)$. (Where $S$ is the spacing of the transversal reinforcement and $d_{b}$ the diameter of the reinforcement at the ends).

The upper beam of the walls was designed to allow the application of vertical load, facilitate lateral load transfer, and prevent local compression failure. The shear-span ratio (M/V.I ) of 2.1 was obtained by applying the lateral load at a height of $2515 \mathrm{~mm}$ from the base of the foundation, approximately at the center of gravity of the upper beam. (Where $\mathrm{M}$ and $\mathrm{V}$ are the applied moment and shear).

\subsection{Materials properties}

The compressive strength of the concrete, $f^{\prime}$, was initially specified at $21 \mathrm{MPa}$, with a slump of $150 \mathrm{~mm}$ and aggregates with a maximum size of $3 / 8^{\prime \prime}$. The actual mechanical properties of the materials were determined through laboratory tests. The average compressive strength of the three cylinders at the age of 28 days was $24.7 \mathrm{MPa}$, and this value was used to calculate the axial load ratio (ALR) applied in the test. Tensile tests were conducted on the electrowelded wire mesh, which had a diameter of $7 \mathrm{~mm}$, and on bars No. 2, No. 4, and No. 5. Table 2 summarizes the properties of the steel reinforcement, and Figure 3 shows the stress-strain curves, in which limited ductility of the wire mesh is observed (Quiroz et al., 2013), (Carrillo et al., 2019).

a)

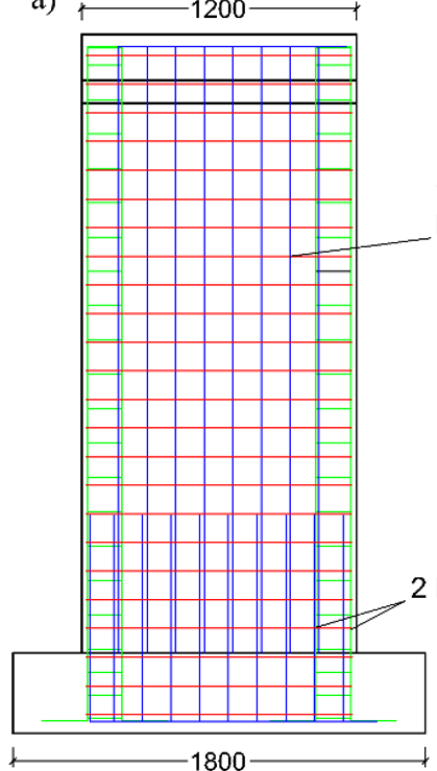

b) $r 300-r$

4 No. 4

E No. $3 \mathrm{c} / 120$

1 No. 2 c/ 125 both directions 2 No. 4

4 No. $5+2$ No. 4 E No. $3 \mathrm{cl} 150$

1 \# $2 \mathrm{c} / 125$ both directions

2 No. 4

g No. 2 c/ 150

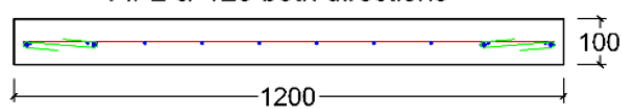

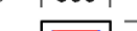
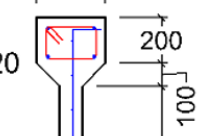

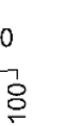

c)

c)

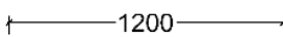

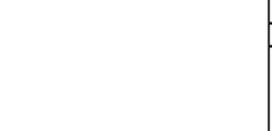

Mesh $\varnothing 7.0 \mathrm{~mm} \mathrm{c/} 150$

100

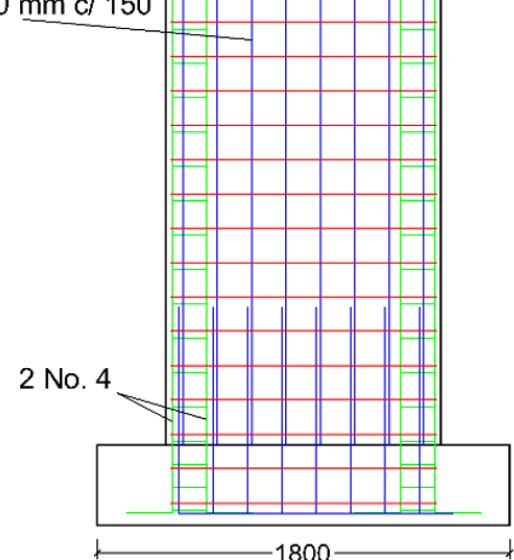

$\longleftarrow 540 \longrightarrow$

$-1800$

Electro-welded mesh $\varnothing 7.0 \mathrm{~mm} \mathrm{c/} 150$

2 No. 4

g No. 2 c/ 150

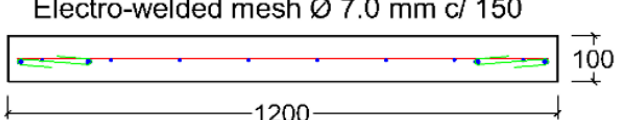

Figure 2. Geometry and reinforcement of the walls: a) MOR10; and b) M1R10.

\subsection{Test setup and instrumentation}

The experimental testing was carried out in the Reaction frame of the School of Civil Engineering and Geomatics at the Universidad del Valle. The intermediate beam of the Reaction Frame has four side supports, two on each side, consisting of metal channels and rollers arranged to restrict out-of-plane displacement at the top of the wall. The rollers were separated from the upper beam of the wall by approximately $2 \mathrm{~mm}$. The lateral restriction simulates buckling bracing generated by the slabs of the buildings, thus conserving the typical slenderness ratio of the wall system $\left(h_{w} / t_{w}=\right.$ 24). A 38.1-mm-thick metal plate was attached to the upper beam of the Reaction frame to hold the four vertical actuators that apply the axial load. These actuators, each with a capacity of $80 \mathrm{kN}$, were connected in parallel and jointed at their ends to apply force on a metal beam, which, in turn, transferred the force to the two load cells located on the 
top of the wall. Figure 4 shows some basic details of the setup. The hinges of the actuators allow horizontal displacement and rotation of the wall during cyclic loading.

Table 2 Properties of steel reinforcement.

\begin{tabular}{cccc}
\hline Properties & Mesh & $\mathbf{N}^{\circ} \mathbf{2}$ & $\mathbf{N}^{\circ} \mathbf{4}$ \\
\hline Yield strength, $\mathrm{f}_{\mathrm{y}}(\mathrm{MPa})$ & 532.7 & 521.1 & 493.0 \\
Maximum strength, $\mathrm{f}_{\mathrm{u}}(\mathrm{MPa})$ & 596.0 & 674.7 & 650.0 \\
Yield strain, $\varepsilon_{\mathrm{y}}$ & 0.0025 & 0.0024 & 0.0026 \\
Ultimate strain, $\varepsilon_{\mathrm{u}}$ & 0.030 & 0.0921 & 0.1196 \\
\hline
\end{tabular}

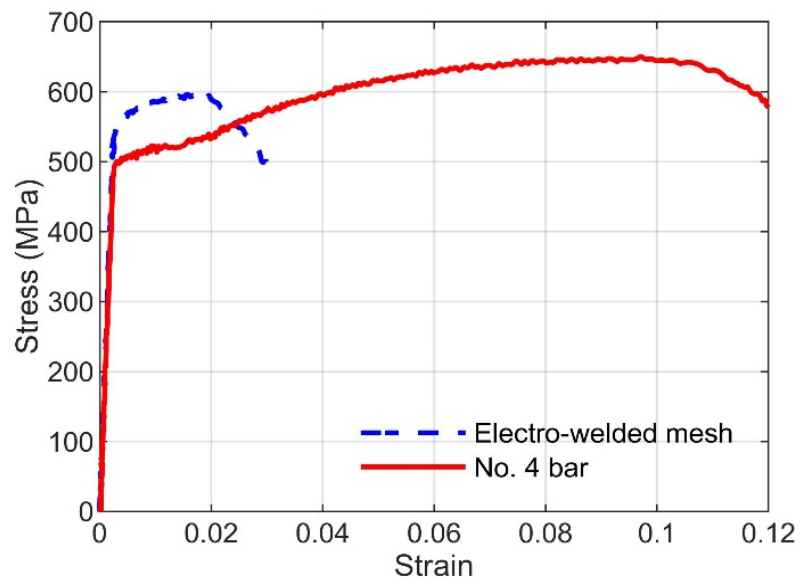

Figure 3. Stress-strain curves of the steel reinforcement.

The walls were anchored to the Reaction frame using ten high-strength ASTM A-197 B7 bars, 19.5 mm in diameter; lateral supports were also installed to restrict possible displacements and rotations at the base. The displacement protocols were executed using the $500 \mathrm{kN}$ capacity Reaction frame actuator, with a maximum stroke of $300 \mathrm{~mm}$. In the upper beam of each wall, two metal rods with bearings were anchored to pull the wall from the ends through tensioners (3/4" threaded bars). The doubly articulated tensioners were connected to the Reaction frame thrust supports to transfer the movement of the actuator to the wall in a controlled manner (Figure 4).

The walls were equipped with four load cells: two were used to monitor the axial load, and two were used to measure the horizontal load caused by the displacement protocol. Seven linear variable differential transformer (LVDT) and fifteen string pots were installed to record displacements in the plane of the wall, possible rotation or displacement of the base, curvature (at heights of 50, 150, and $300 \mathrm{~mm}$ ), shear deformations, and out-of-plane displacement at three locations on the wall. The devices for monitoring the overall response of the wall were attached to two metallic frames anchored to the testing frame base but were independent of its movement. Twelve strain gauges were attached to the concrete surface to measure strains in the region of greatest stress concentration on each side of the wall. Figure 5 shows a diagram of the instrumentation.

\subsection{Procedure for monotonic and cyclic tests}

The axial load was applied by controlling the magnitude of the force, and the lateral load was controlled by the displacement. The monotonic test of the wall M0R10 started with the application of $59 \mathrm{kN}$ vertical load, corresponding to $2 \%$ of the nominal compressive capacity of the wall. The axial load remained constant by control the hydraulic pressure in the actuators. Subsequently, the wall was moved laterally by the system of tensors until its failure. Wall M0R10 strength degradation was not captured since it was necessary to remove sensors to avoid their damage during large displacement, and hence the last part of the curve was not be reliably recorded. However, it was possible to continue recording damage evolution and cracking patterns up to the failure of the wall. For the cyclic loading test of the wall M1R10, a constant $260 \mathrm{kN}$ vertical load, equivalent to an axial load ratio of $9 \%$, was applied and maintained. This load corresponds approximately to the average service load $(D+L)$ expected in the first level of a wall in a twelve-story building. Subsequently, the displacement protocol was implemented for ten phases. Each phase included two cycles of equal amplitude, with lateral drift increments from $0.15 \%$ to $3 \%$ (Figure 6). The protocol execution speed was controlled 
to reduce dynamic effects, enable constant inspection of the operation of the hydraulic system, and record the damage progress and level of cracking on each side of the wall. (Where $D$ and $L$ are the dead and live loads, respectively).

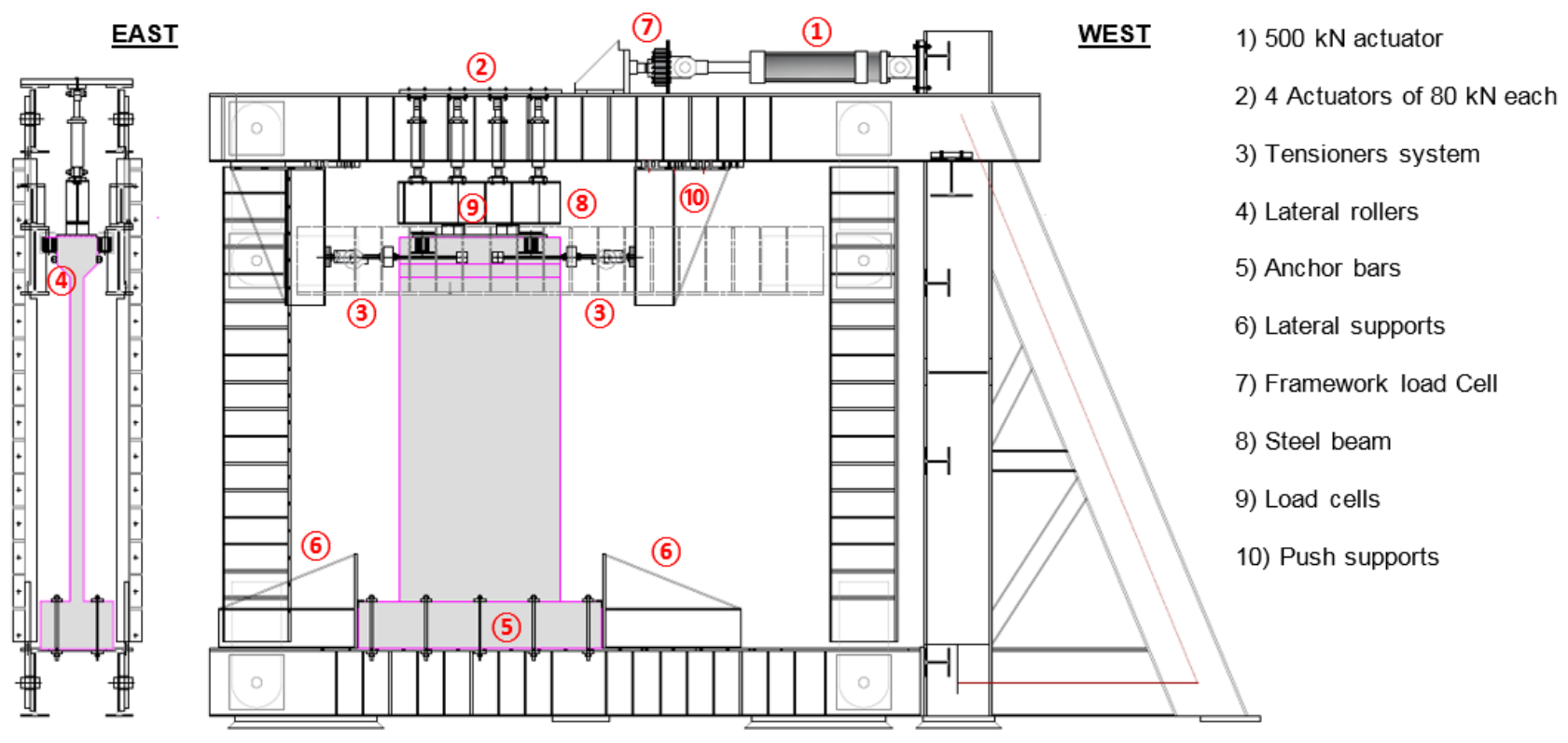

Figure 4. Setup of a wall in the Reaction frame
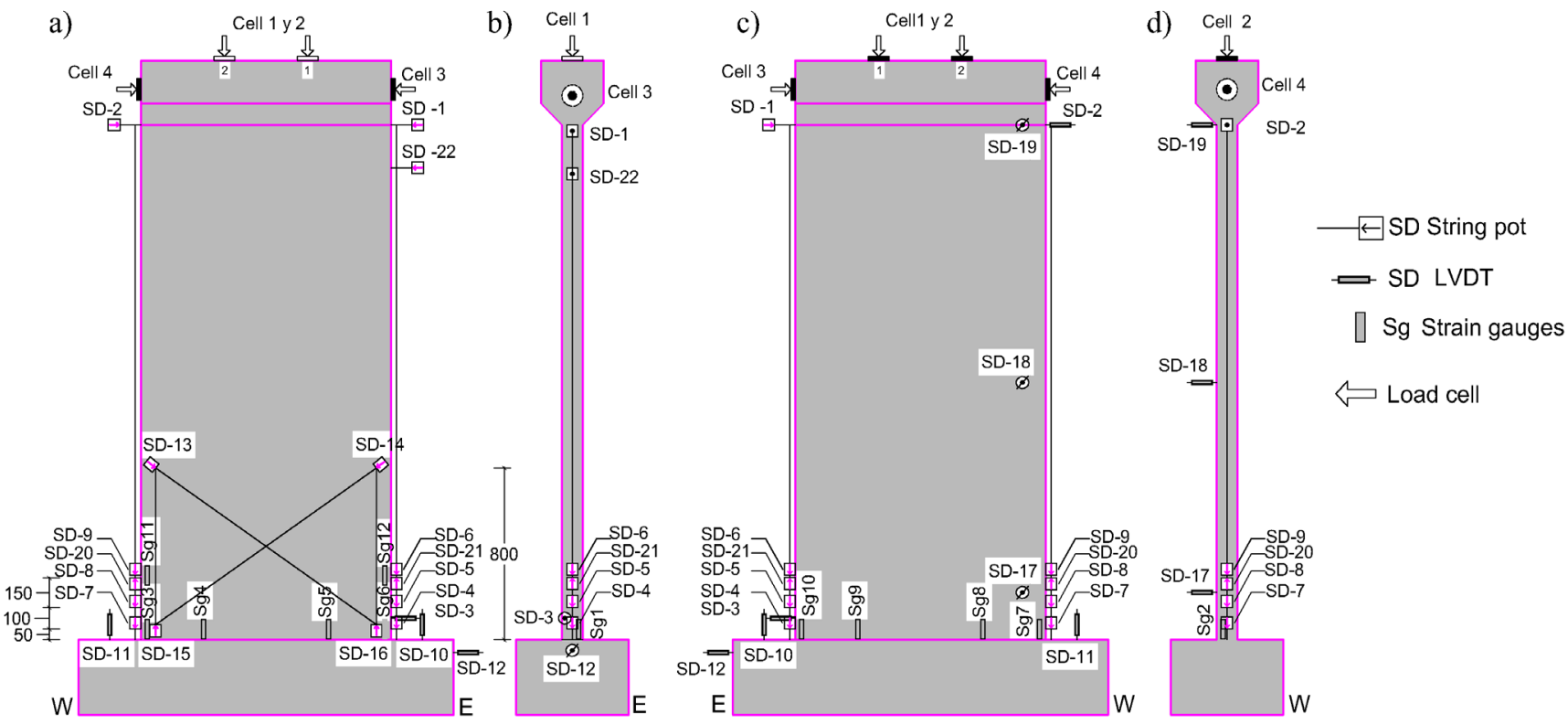

Figure 5. Instrumentation: a) South side; b) East side; c) North side; and d) West side.

\section{EXPERIMENTAL RESULTS}

\subsection{Wall MOR10 - Monotonic test}

\subsubsection{Force-lateral drift relationship of wall MOR10}

The force-lateral drift response of wall MOR10 is shown in Figure 7. The displacement and load were recorded with displacement sensors SD1 and SD2 and cells C3 and C4, respectively (Figure 5). Table 3 summarizes the points corresponding to the first cracking, yield, and maximum strength of the walls. $V_{c r}, \Delta_{c r}, V_{y}$, and $\Delta_{y}$ correspond to the lateral load and drift at the first cracking and yielding point, and $V_{\max }$ and $\Delta_{\max }$ are the maximum strength and the corresponding drift. $\Delta_{u}$ is the lateral drift at the failure point, and $\mu_{\Delta}$ is the displacement ductility, defined as the ratio of maximum displacement $\left(\Delta_{\mathrm{u}}\right)$ to the corresponding displacement at the onset of yielding $\left(\Delta_{\mathrm{y}}\right)$. The experimental shear forces and 
drifts were obtained according to the definitions proposed for the ACl 445B Shear Wall Database (Usta et al., 2017), that is, according to the envelope or pushover curve of each wall.

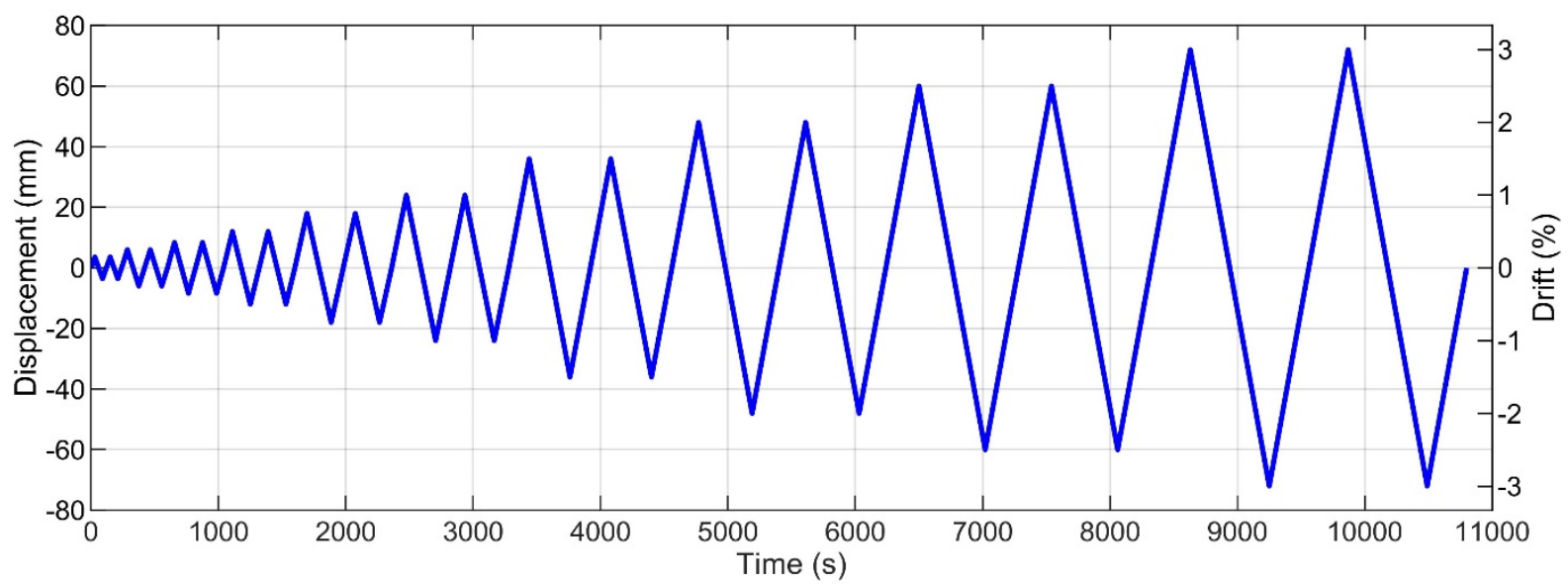

Figure 6. Displacement protocol for the cyclic loading test of wall M1R10.

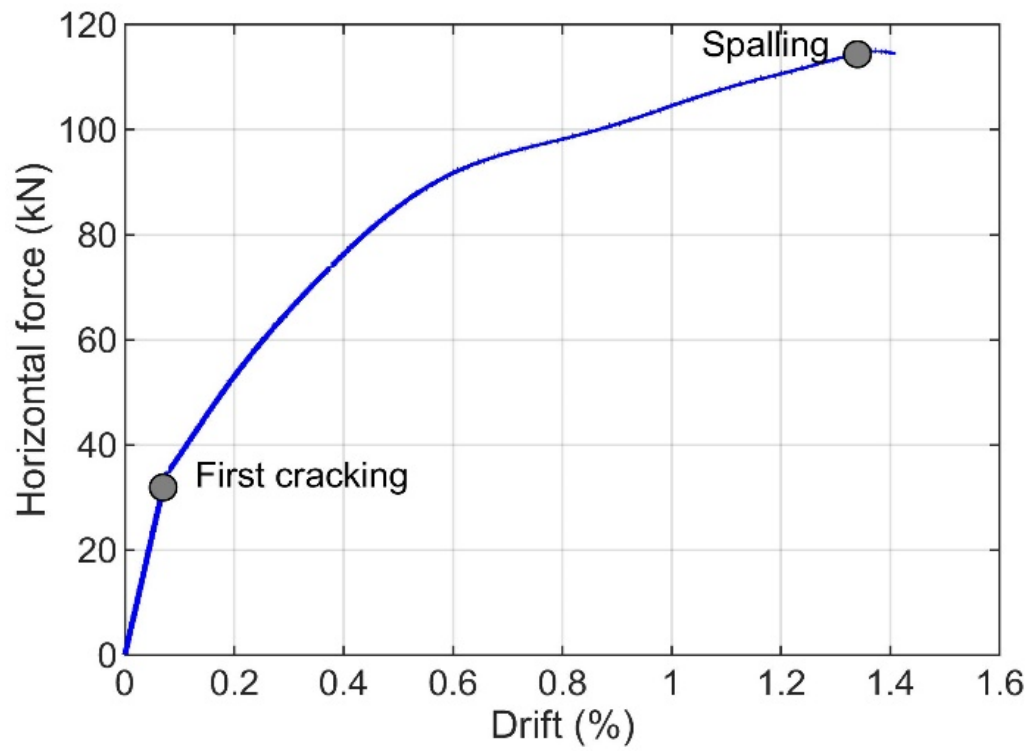

Figure 7. Force vs. lateral drift of wall MOR10.

Table 3 Experimental shear and drifts of walls.

\begin{tabular}{ccccccccccc}
\hline Wall & ALR & $\mathbf{V}_{\text {cr }}(\mathbf{k N})$ & $\boldsymbol{\Delta}_{\mathrm{cr}}(\%)$ & $\mathbf{V}_{\mathbf{y}}(\mathbf{k N})$ & $\boldsymbol{\Delta}_{\mathrm{y}}(\%)$ & $\mathbf{V}_{\max }(\mathbf{k N})$ & $\boldsymbol{\Delta}_{\max }(\%)$ & $\boldsymbol{\Delta}_{\mathrm{u}}(\%)$ & $\boldsymbol{\mu}_{\Delta}$ \\
\hline M0R10 & 0.02 & 34.1 & 0.07 & 95.0 & 0.69 & 114.7 & 1.36 & - & - \\
M1R10 & 0.09 & 60.1 & 0.13 & 124.6 & 0.59 & 151.7 & 1.08 & 1.61 & 2.7 \\
\hline
\end{tabular}

\subsubsection{Damage evolution and failure mode of wall MOR10}

The first crack was observed $50 \mathrm{~mm}$ from the base at a drift of $0.07 \%$, with a thickness of $0.10 \mathrm{~mm}$. For drifts greater than $0.15 \%$, horizontal cracks were observed at the wall base. From a drift of $0.5 \%$, flexural-shear cracks appeared, with thicknesses up to $0.50 \mathrm{~mm}$ and inclinations of up to $45^{\circ}$. Subsequently, the wall began to detach from its base. The first vertical cracks in the wall base, indicative of the onset of concrete spalling, were observed at a drift of $1.34 \%$. For larger displacements, spalling progressively continued, and crushing of the concrete occurred. Finally, the reinforcement of the boundary elements was exposed and began to buckle immediately. The wall reinforcement did not fracture. The buckling of the reinforcement extended until the longitudinal web reinforcement. The wall behavior and the failure mode were controlled by bending, according to its aspect ratio $\left(h_{w} / I_{w}=2\right)$ and the shear span ratio $\left(M / V . I_{w}=2.1\right)$. The yield point of the longitudinal reinforcement was reached before concrete crushing or the appearance of any evidence of lateral buckling in the reinforcement bars. Figure 8 shows the final state of the wall. 
a)

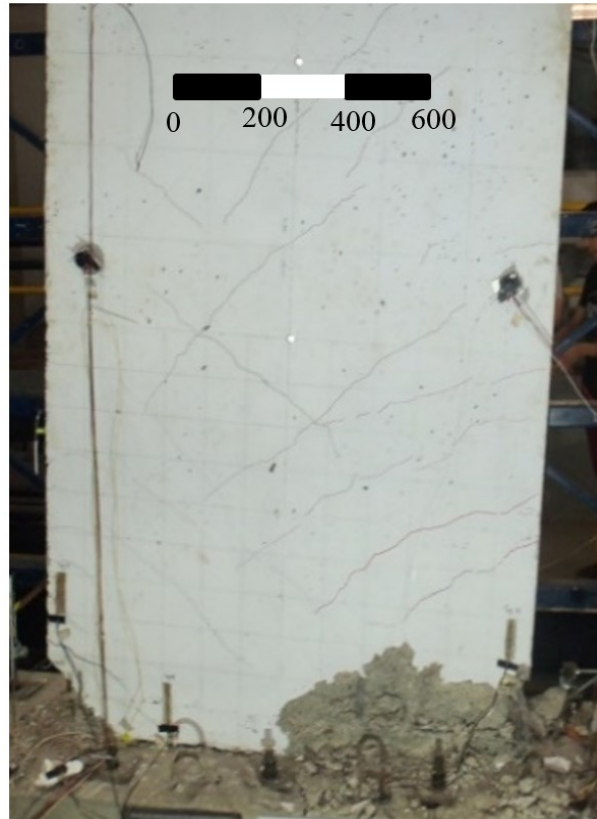

b)

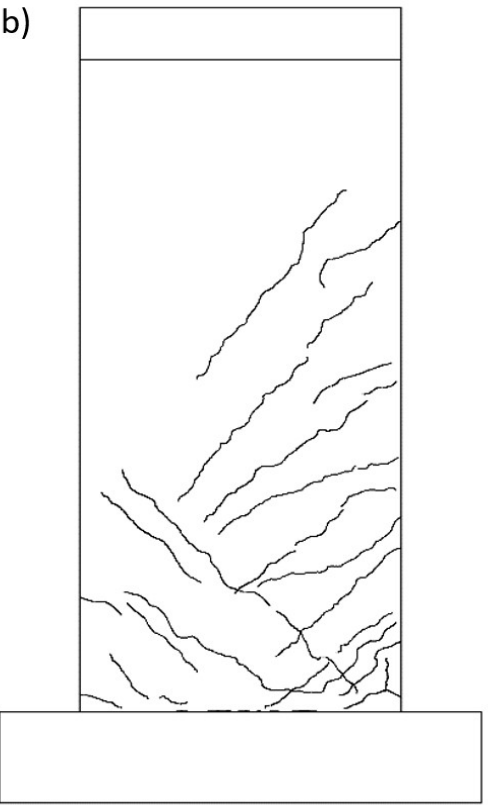

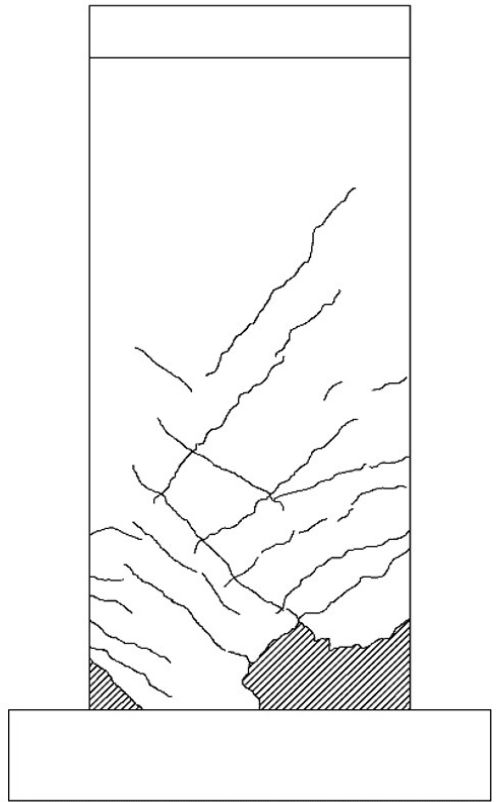

Figure 8. a) Final state at the south side of wall MOR10; and b) cracking pattern on the north and south sides.

\subsection{Wall M1R10 - Cyclic test}

\subsubsection{Hysteretic response of wall M1R10}

The hysteretic response of the M1R10 wall in terms of force vs. drift and its envelope curve are shown in figure 9. The maximum strength, $V_{\max }$, was obtained as the highest lateral load attained during the test, and the nominal failure or ultimate strength, $V_{u}$, was determined at the instant the lateral strength degraded to $80 \%$ of the maximum strength. Table 3 shows the values of the most significant points of the hysteretic response of the wall.

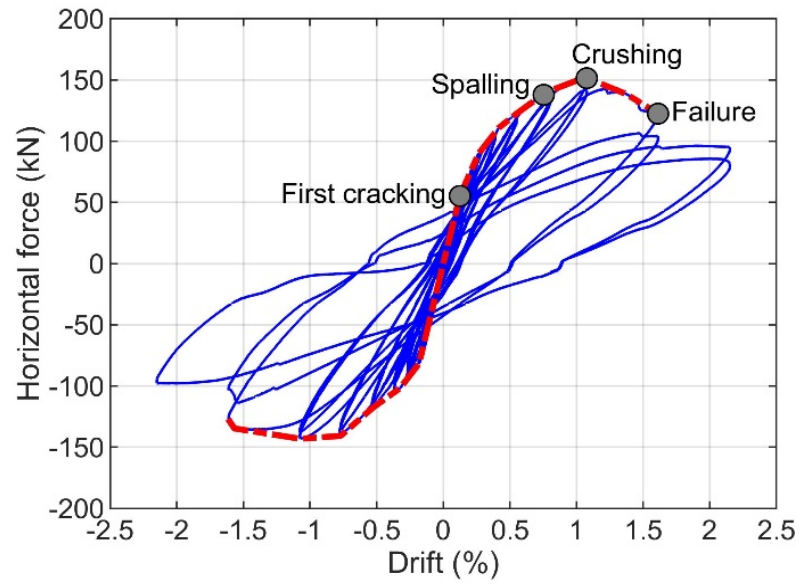

Figure 9. Force vs. drift relationship and main points and damage states of wall M1R10.

\subsubsection{Damage evolution and failure mode of wall M1R10}

The first crack in this wall was observed $45 \mathrm{~mm}$ from the wall base for a drift of $0.13 \%$. For greater displacements, new flexure-shear cracks appeared on both wall ends with thicknesses of up to $0.45 \mathrm{~mm}$ and inclinations up to $45^{\circ}$. The first signs of spalling occurred at a drift of $0.75 \%$. Concrete crushing began at a drift of $1.08 \%$. For a drift of $1.5 \%$, the cracking and progressive spalling of the concrete caused reinforcement exposure, which almost immediately resulted in buckling of the longitudinal reinforcement due to a lack of lateral support and the high $S / d_{b}$ ratio (Dazio et al., 2009). For this drift, the onset of fracture of the web reinforcement was also detected. For a $2 \% \mathrm{drift}$, buckling of the reinforcement continued, the wall detached completely from the base, and finally, one of the exposed bars in the boundary element fractured. Similar to wall MOR10, the behavior of this wall was dominated by bending, according to its dimensions and 
shear-span ratio. Also, the yield point of the longitudinal reinforcement was reached before concrete crushing. Figure 10 shows the final state of the wall.

a)

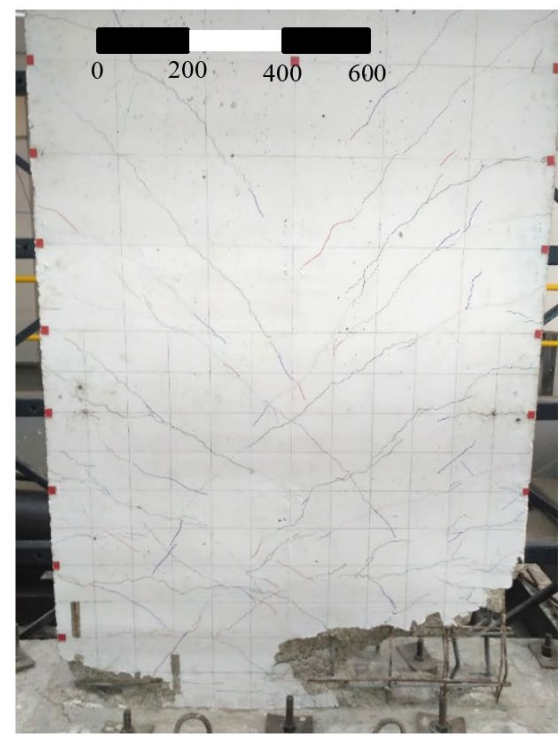

b)

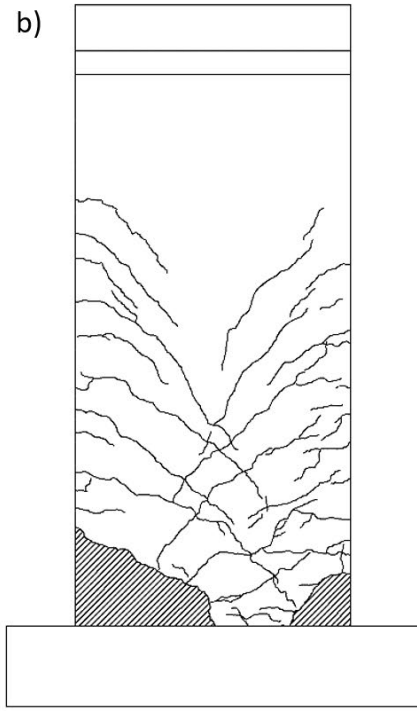

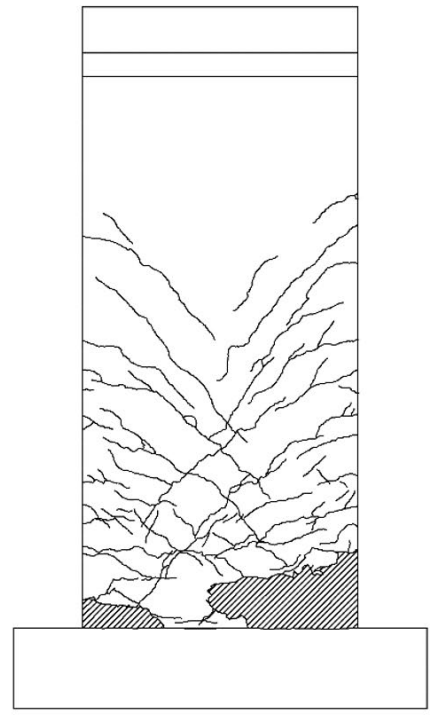

Figure 10. a) Final state on the south side of wall M1R10; and b) cracking pattern of the north and south sides.

\section{RESULTS AND DISCUSSION}

\subsection{Plastic hinge length}

Strains in the concrete were recorded at twelve points of the wall base (Figure 5). Figure 11a shows the strains in the concrete registered with gauges Sg7 and SG11 at the wall base and a height of $300 \mathrm{~mm}$, respectively. It can be noted that the strains were lower for gauge SG11, which was located until where the damage concentration was expected (300 mm from the base). In Figure 11a, the first few seconds of the test correspond to the application of the vertical load, which caused an average compressive strain in the concrete of 0.00017 . The experimental length of the plastic hinge can be estimated as the distance between the base and the top edges of the area affected by spalling during failure (Alarcon et al., 2014). For wall M1R10, the damage spread to an average height of $250 \mathrm{~mm}$ from the base, as shown in Figure 11b. From records from strain gauges Sg7 and Sg11, in Figure 11a, it was possible to confirm the length of the plastic hinge. Assuming strain in concrete is the same as in reinforcing bars at the same level, it can be seen that gauge Sg11, located $300 \mathrm{~mm}$ above the wall base, did not reach strains greater than 0.0026 . It implies that the reinforcing steel did not exceed the yield point, and the concrete did not attain the spalling damage level. The same result was observed in the monotonic test of wall MOR10, in which the spalling advanced to an average height of $250 \mathrm{~mm}$, as shown in Figure 12. The experimentally obtained length of the plastic hinge $\left(I_{\mathrm{p}}\right)$ matches the results registered for similar walls in other studies (Takahashi et al., 2013), (Alarcon et al., 2014), (Wallace et al., 2012), (Wallace et al., 2016), in which it has been found that the concentration of damage frequently occurs a height of two to three times the wall thickness $\left(I_{p}=2.5 * t_{w}=250 \mathrm{~mm}\right)$. These results are relevant, not only for the fitting of the proposed numerical model but for the general characterization of the behavior of the RCTW, since it is confirmed that the length of the plastic hinge is considerably less than that obtained by the expressions proposed for reinforced concrete walls (e.g., $0.5 \mathrm{I}_{\mathrm{w}}$ ).

\subsection{Stiffness evaluation}

Table 4 compares the theoretical lateral stiffness ( $\left.K_{\text {theor }}\right)$ and the initial experimental stiffness $\left(K_{0}\right)$ of the walls. The $\mathrm{K}_{\text {theor }}$ was calculated, according to Equation (2), where $\mathrm{E}$ is the modulus of elasticity (3900vf' ${ }^{\prime}$ ), $\mathrm{G}$ is the shear modulus, and $\alpha$ is the shear form factor. The values of these parameters were $19.4 \mathrm{GPa}, 7.8 \mathrm{GPa}$, and 1.2, respectively. To cyclic test, the initial experimental stiffnesses $\mathrm{K}_{0}+$ and $\mathrm{K}_{0}$ - were estimated as the ratio between the shear force and the displacement for the first level of drift for the positive and negative parts of a cycle, respectively. As shown in Table 4, there are considerable differences between theoretical stiffness and experimentally obtained stiffness, which can be explained mainly for two reasons: i) for the first level of drift $\Delta 1$, a moment $M_{\Delta 1}$ greater than the moment of cracking, Mcr, was reached, which caused the first flexural cracks to appear and reduced the effective inertia of the section, and ii) concrete cracking due to drying shrinkage, before the test may have contributed to the initial stiffness reduction of 
the wall, as indicated by Quiroz et al. (2013). The initial stiffness obtained experimentally is on average $44 \%$ of the theoretical stiffness. It is important to note that similar results have been reported in other tests (Quiroz et al., 2013), (Hube et al., 2014).

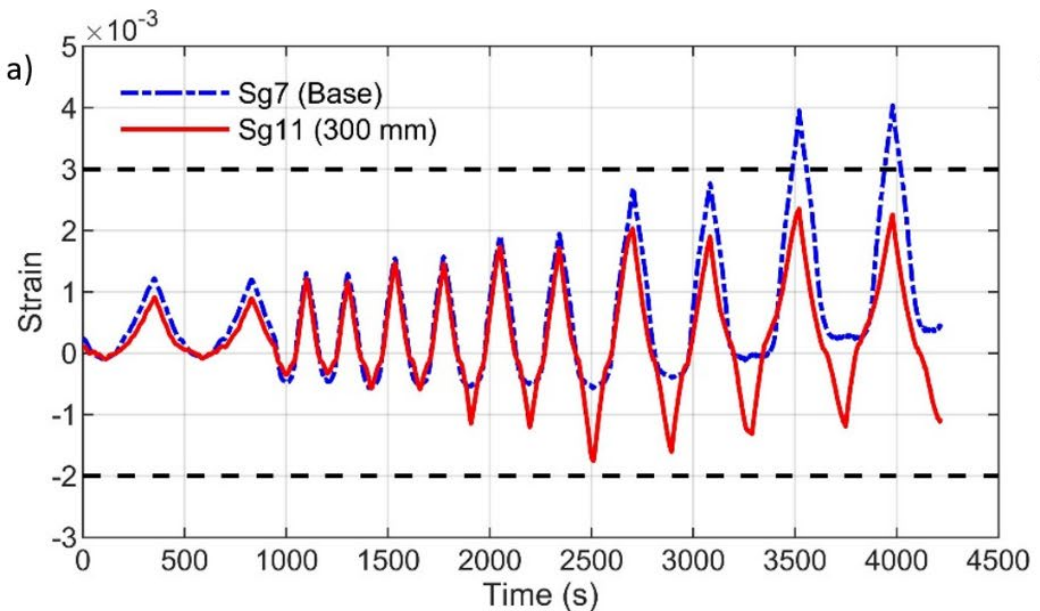

b)

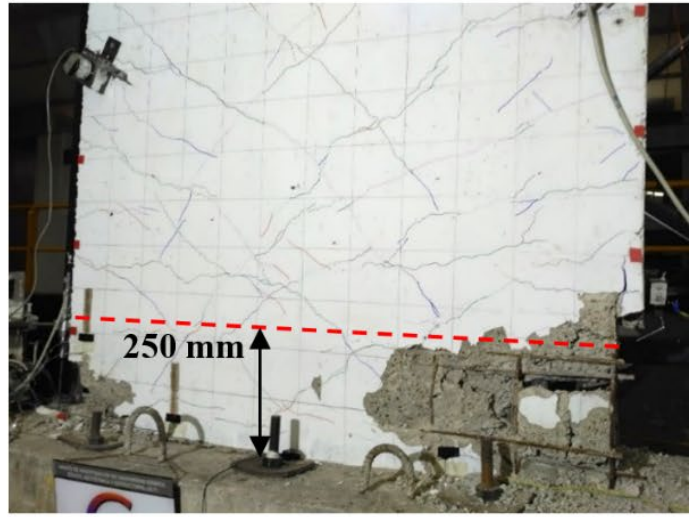

Figure 11. a) Strains in the concrete from gauges Sg7 (base) and Sg11 (at $300 \mathrm{~mm}$ ); and b) the plastic hinge in wall M1R10.

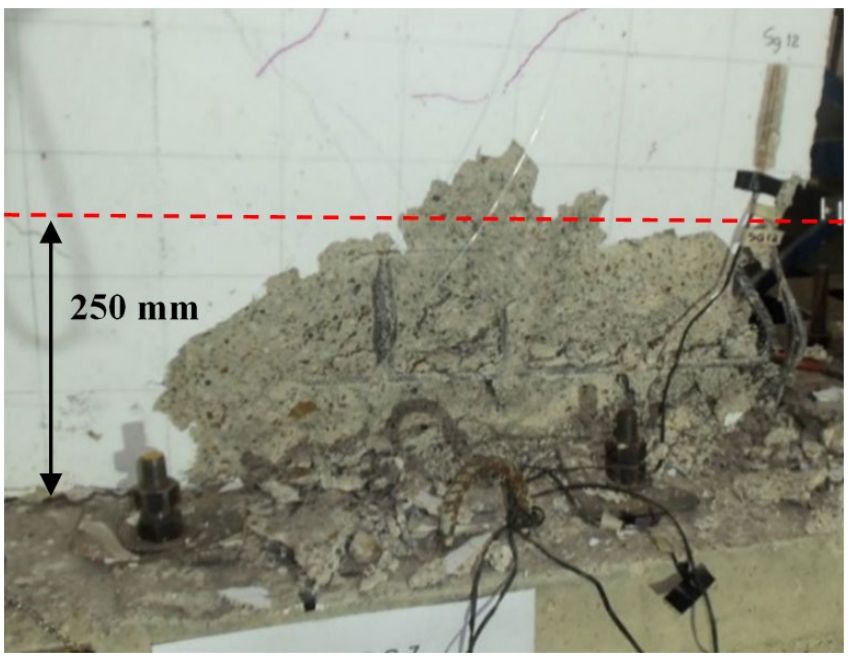

Figure 12. Plastic hinge of wall MOR10.

Table 4 Initial stiffnesses comparison

\begin{tabular}{|c|c|c|c|c|c|}
\hline \multirow{2}{*}{ Wall } & $\mathrm{K}_{0}^{+}$ & $\mathrm{K}_{\mathbf{0}}^{-}$ & $\mathbf{K}_{\text {theor }}$ & \multirow{2}{*}{$\mathrm{K}_{0}{ }^{+} /$theor } & \multirow{2}{*}{$\mathrm{K}_{0}-\mathrm{K}_{\text {theor }}$} \\
\hline & (kN/mm) & $(\mathrm{kN} / \mathrm{mm})$ & $(\mathrm{kN} / \mathrm{mm})$ & & \\
\hline MOR10 & 19.0 & - & 42.6 & 0.45 & - \\
\hline M1R10 & 18.6 & 17.9 & 42.6 & 0.44 & 0.42 \\
\hline
\end{tabular}

$K=\frac{t_{w}}{\frac{4}{E}\left(\frac{h_{w}}{l_{w}}\right)^{3}+\frac{\alpha}{G}\left(\frac{h_{w}}{l_{w}}\right)}$

Figure 13 shows the lateral stiffness degradation as a function of drift. Figure $13 \mathrm{~b}$ shows the ratio between the initial experimental stiffness of the wall, $\mathrm{k}_{0}$, and the stiffness in each cycle or drift level, $\mathrm{k}_{\mathbf{i}}$. The points corresponding to drifts of $0.5 \%$ and $1 \%$, the maximum strength, and the failure condition are also specified. For wall M1R10, the stiffness degradation from one phase to the next was, on average, 25\%. For wall MOR10, stiffness degradation was more severe. When a drift of $0.5 \%$ has reached the stiffness for wall MOR10 is reduced to $37 \%$ of its initial stiffness, while the stiffness for wall M1R10 is reduced to $53 \%$ of its initial stiffness on average. When a drift of $1 \%$, limit established by Regulation NSR-10, is reached, wall MOR10 has lost 77\% of its initial stiffness, and wall M1R10 has lost $67 \%$ of its initial stiffness. For a drift limit of $1.43 \%$, as specified by the regulation for buildings designed with cracked sections, the stiffness loss of wall 
M1R10 is $78 \%$. It is evidence of an abrupt deterioration in stiffness due to progressive concrete cracking. A probable reason for the stiffness degradation in the wall MOR10 to be greater than in the wall M1R10, despite the difference in the type of test, monotonic and cyclic, respectively, was the axial load ratio. For the first wall, the ALR was $2 \%$, and for the second was $9 \%$. The lower axial load caused the lateral load resistance of the wall MOR10 to be lower, and to reach a more ductile behavior, also that the degradation of the stiffness was more severe, suggesting that for lower ALR, the stiffness degradation tends to increase. A similar trend was observed in Blandón and Bonett (2020) and Looi et al. (2017).

a)

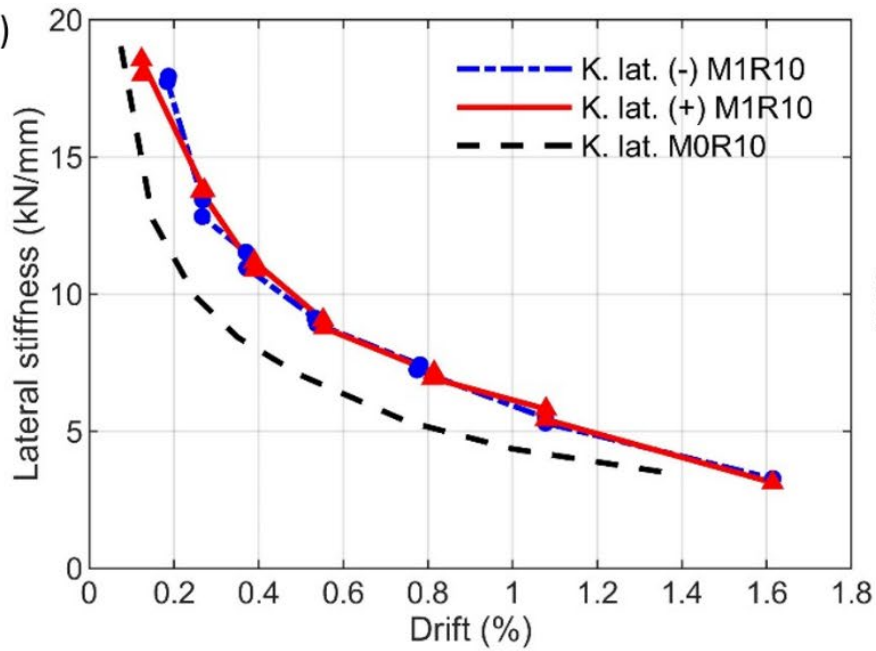

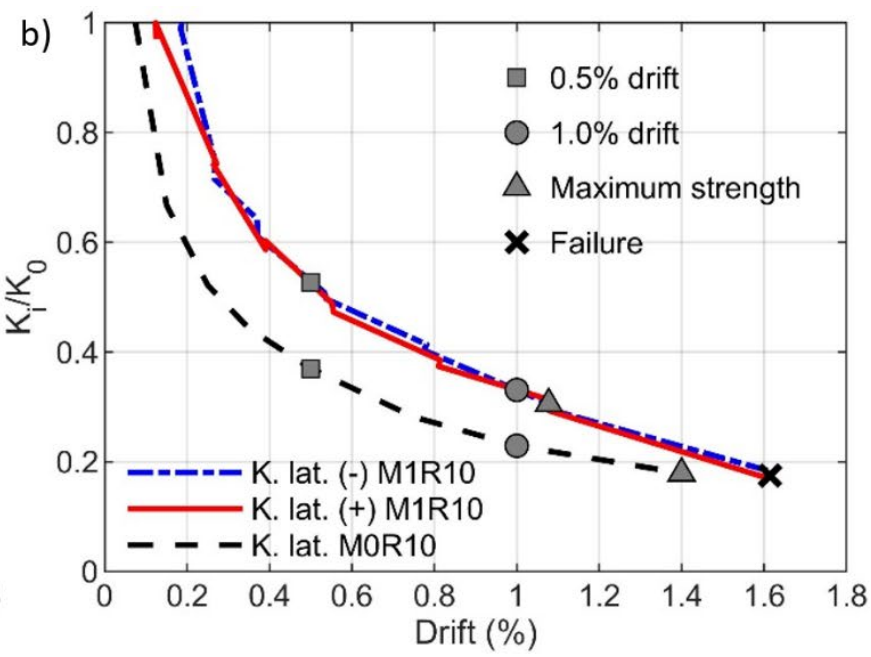

Figure 13. a) Stiffness degradation; and b) normalized stiffness degradation.

The observed stiffness degradation is comparable to that reported by Blandón et al. (2015), Quiroz et al. (2013), y Blandon et al. (2018) for walls with similar characteristics. In these investigations, a reduction of the initial stiffness of $80 \%, 84 \%$, and more than $90 \%$ was reported, for a drift of $1 \%, 0.5 \%$, and $1 \%$, respectively. These results are relevant since lower cracking levels are used for wall design with cracked sections, such as those proposed by the $\mathrm{ACl} 318-14$ ( $\mathrm{ACl}$ Committee 318, 2014). This code establishes that the effective inertia to an elastic analysis is $0.7 \mathrm{I}$ for non-cracked sections and $0.35 \mathrm{Ig}$ for cracked sections. (where $\mathrm{I}_{\mathrm{g}}$ is the gross inertia of the section).

\subsection{Behavior out-of-plane}

No signs of out-of-plane buckling were observed in the wall M1R10. The displacements recorded by sensors SD17 to SD19 (Figure 5) were not significant. The parameter governing out-of-plane instability is the magnitude of tensile strain at the wall ends before the subsequent compressive load (Paulay \& Priestley, 1993). According to Equation (2) from Parra \& Moehle (2017), the tensile strain, $\epsilon_{s m, c r}$, which would induce out-of-plane instability for wall M1R10, would be in the order of 0.011 . The tensile strains recorded in the test were higher than this value only at the base of the wall, therefore despite the high slenderness ratio of the wall $\left(h_{w} / t_{w}=24\right)$, it is feasible that out-of-plane buckling did not occur because there were not enough height-distributed cracks at the ends of the walls that would lead to lateral instability. This is likely due to the concentration of plasticity at the wall base in a main crack at the wall-foundation interface, which caused the tensile strains at locations above that level not to exceed the theoretical strain that induces instability. Another aspect that may contribute to this phenomenon, besides the type of electro-welded reinforcement used in the web, is the moderate longitudinal reinforcement ratio at the wall ends $\left(\rho_{b}=1.46 \%\right)$. It has been determined numerically (Parra \& Moehle, 2017) and experimentally through tests on columns (Rosso et al., 2018) that with high reinforcement ratios in the boundary elements of the walls present significantly greater displacements out-of-plane, and an earlier failure is generated than in the case of walls with low reinforcement ratios. In Equation (2), k $=0.5$ corresponds to walls with a single reinforcing curtain, and the $\boldsymbol{K}$ factor was taken as 0.5 , assuming a fixed-fixed condition in the upper beam and the wall foundation.

$\epsilon_{s m, c r}=\mathrm{k} \xi_{\mathrm{cr}}\left(\frac{\pi t_{w, c r}}{K h_{w}}\right)^{2}+0.005 \quad \xi_{\mathrm{cr}}=0.5\left(1+\frac{2 m}{0.85}-\sqrt{\left(\frac{2 m}{0.85}\right)^{2}+\frac{4 m}{0.85}}\right) \quad m=\rho \frac{f_{y}}{f^{\prime} c}$ 


\subsection{Energy and damage assessment of wall M1R10}

During cyclic load tests, similar to the demands exerted in an earthquake, element damage and dissipated energy are closely related. The energy dissipation capacity of a structural element can be calculated as the deformation energy stored in each hysteresis cycle, and damage can be estimated as a linear combination of the damage caused by deformation and that generated by repeated cyclic loading effect. For wall M1R10, dissipated energy, cumulative dissipated energy, and Park-Ang damage index (Park et al., 1984) were calculated. Figure 14 shows that the dissipated energy before the yield point (drift of $0.59 \%$ ) is very low and that from that point, the dissipated energy increases from $600 \mathrm{~J}$ to approximately $5700 \mathrm{~J}$ at the failure point. It can also be seen that in the first cycles, of each drift level, more energy is dissipated than in the second cycles.
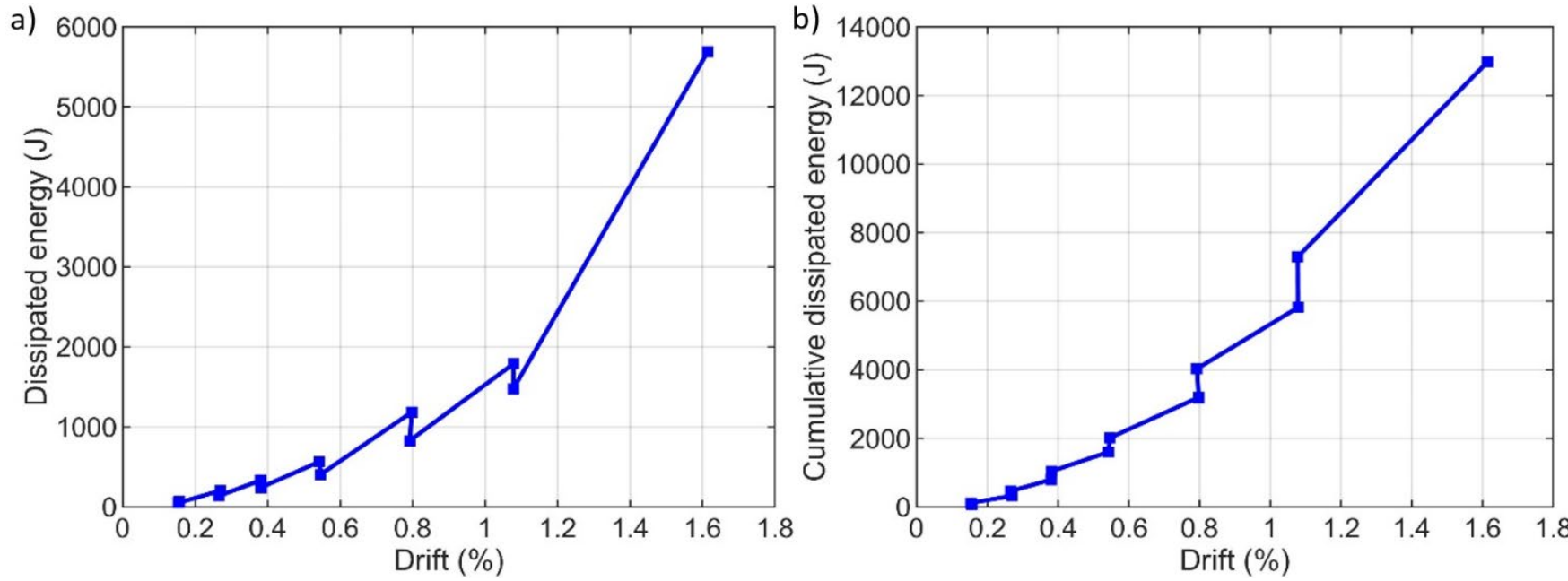

Figure 14. Energy vs. Drift wall M1R10: a) dissipated energy; and b) cumulative dissipated energy.

The Park-Ang damage index (DI) was calculated up to the nominal point of failure using Equation (3). Figure 15 shows the relationships of damage index as a function of drift. The damage index is one of the most widely used indices because it allows including the effect of the damage in the structural elements, not only due to the maximum displacement reached but also to the dissipated energy (Diaz et al., 2017), besides it relates a damage value calculated with the physical damage that a structure can suffer for a seismic event (Table 5). In Equation (3), $\beta$ is a non-negative parameter representing strength degradation, which has an approximate value of 0.1 for welldesigned reinforced concrete elements (Elmenshawi \& Brown, 2010), dE is the hysteretic dissipated energy, $\delta_{i}$ and $\delta_{f}$ are the displacements in each cycle $i$ and the ultimate displacement, and $V_{y}$ is the lateral force at the yield point. The damage index, DI, was calculated for $\beta=0.10$. Figure 15 shows the degrees of damage according to the Park et al. (1987) scale (Table 5). The damage description of the scale correlates well with the damage that occurred during the test. It is observed that for a $1 \%$ drift, the damage index is $56 \%$, corresponding to a severe and unrepairable damage state.

Table 5 Proposed damage scale by Park et al., 1987.

\begin{tabular}{cccll}
\hline Damage level & Degree of damage & DI, Damage index (\%) & Damaged state & \multicolumn{1}{c}{ Description } \\
\hline 1 & Slight & $<10$ & & Localized minor cracks \\
2 & Minor & $10-25$ & Repairable & Slight cracks in the entire structure \\
3 & Moderate & $25-40$ & Severe cracks and localized spalling \\
\hline 4 & Severe & $40-100$ & Total loss & Concrete crushing, visible reinforcement. \\
5 & Collapse & $>100$ & Collapse \\
\hline
\end{tabular}

$D I=\frac{\delta_{i}}{\delta_{f}}+\beta \frac{\int \mathrm{dE}}{V_{y} \cdot \delta_{f}}$ 


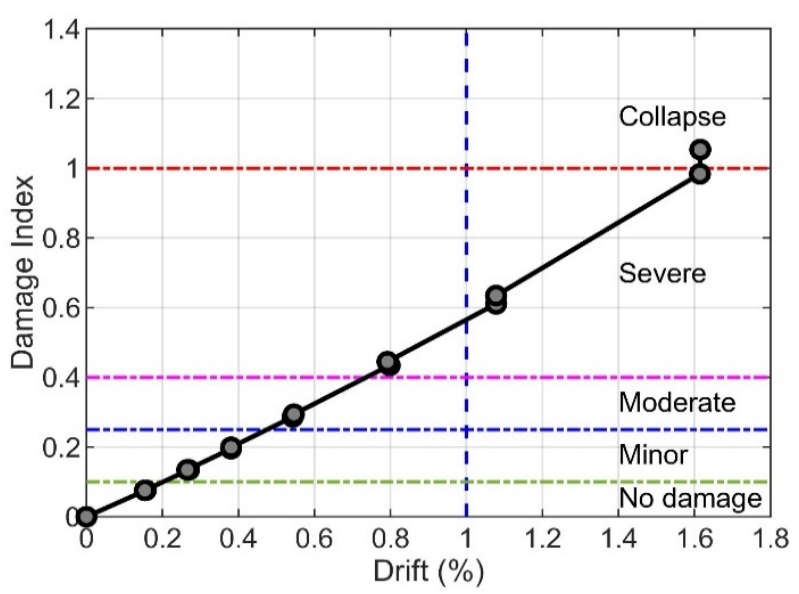

Figure 15. Park-Ang damage Index of Wall M1R10.

\section{ANALYTICAL SIMULATION}

\subsection{Model description}

In the numerical modeling, the analytical response of the walls subjected to cyclic loading was simulated by representing the experimental conditions using the Multiple Vertical Line Element Model (MVLEM) supported by the OpenSees platform (Mazzoni et al., 2009). This macro model was developed by Vulcano et al. (1988), and additional characteristics were included by Kolozvari and Wallace (2016) to improve the response in terms of the shear and flexure in inelastic conditions. The model considers the degradation of both the strength and the stiffness through the constitutive model used for the reinforcing steel and the effect of the gradual closing of the cracks in the concrete through its constitutive model. An MVLEM element includes six degrees of freedom, with three in the center of each of the rigid beams located at the bottom and top of that element, as shown in Figure 16. The axial and flexural response of each MVLEM element is simulated by a series of vertical uniaxial elements connected to the bottom and top rigid beams. All vertical springs obey the same constitutive laws of their materials, and each of them develops its history independently in terms of deformations, stiffness degradation, and resistance according to cyclic constitutive models for reinforcing steel, concrete, and its tributary area. The rigid beams at the top and bottom of each MVLEM element are responsible for receiving the deformations induced by each vertical spring and translating it into the overall response of the MVLEM element according to the assumption that the plane sections remain plane. The shear behavior of each MVLEM element is taken into account by a horizontal spring, with a specific linear relationship of force versus deformation, located at a height ch from the base and decoupled from vertical uniaxial elements.

Relative rotation between the base and the top of each element occurs around a point located in the central axis of the element at height ch. The rotation and transverse displacements are calculated based on the wall curvature, which depends on the geometric and mechanical characteristics corresponding to the flexion at the height ch of each element. The value selected for the variable $c$, equal to 0.4 , was made according to the recommendations given by Vulcano et al. (1988) and verified by Orakcal et al. (2004), based on comparisons made between the responses of the MVLEM model and experimental results. Inelastic constitutive models were defined for each material. The model proposed by Mander et al. (1988) was used for the concrete, and the model called Hysteretic Material in OpenSees was used for the steel (Scott \& Filippou, 2016). The mechanical properties of the concrete and the reinforcing steel used in the models were obtained from laboratory tests of these materials. The discretization of the models was carried out with four MVLEM elements in height, composed of five vertical macroelements, as shown in Figure 17. The curvature distribution in height is assumed to be uniform, as seen in Figure 16, and since each of the MVLEM elements is independent of the others, it is assumed that the first element at the bottom will concentrate a greater demand for curvature, being able to represent the plastic hinge observed in the experiment.

\subsection{Model parameters}

The required parameters by the MVLEM model are summarized in five aspects: i) the geometry and arrangement of the longitudinal reinforcement of the wall, ii) the mechanical properties and the constitutive models of concrete and steel, iii) loading conditions and imposed displacements, iv) discretization in MVLEM elements and v) shear response mechanism. The most sensitive parameters for fitting the model are mainly those corresponding to the definition of the 
constitutive material models. ConcreteCM model was used for concrete, for which the following variables must be provided, in addition to the basic mechanical properties: shape parameter for compression $\left(r_{c}\right)$, the critical strain on the compression envelope curve $\left(\varepsilon_{\mathrm{cr}}^{-}\right)$, shape parameter for tension $\left(r_{\mathrm{t}}\right)$, and critical strain on the tensión envelope curve $\left(\varepsilon^{+} \mathrm{cr}\right)$. These variables define the characteristics of the concrete envelope, and the variables: secant modulus $\left(E_{\mathrm{sec}}\right)$, plastic modulus $\left(E_{\mathrm{pl}}\right)$, stress, and strain offsets $\left(\Delta_{\mathrm{f}}\right.$ y $\left.\Delta_{\mathrm{e}}\right)$ for tensión and compression, define the hysteretic behavior. For reinforcing steel, the Hysteretic Material model was used. This model can be bilinear or trilinear as the representative points of the monotonic stress-strain diagram are determined, and similar to concrete, in addition to its basic properties, it must be included: pinching factor for strain during reloading ( pinch $_{\mathrm{x}}$ ), pinching factor for stress during reloading (pinchy), damage due to ductility (damage1), damage due to energy (damage2), and exponent for stiffness degradation on the unloading based on ductility (Beta).

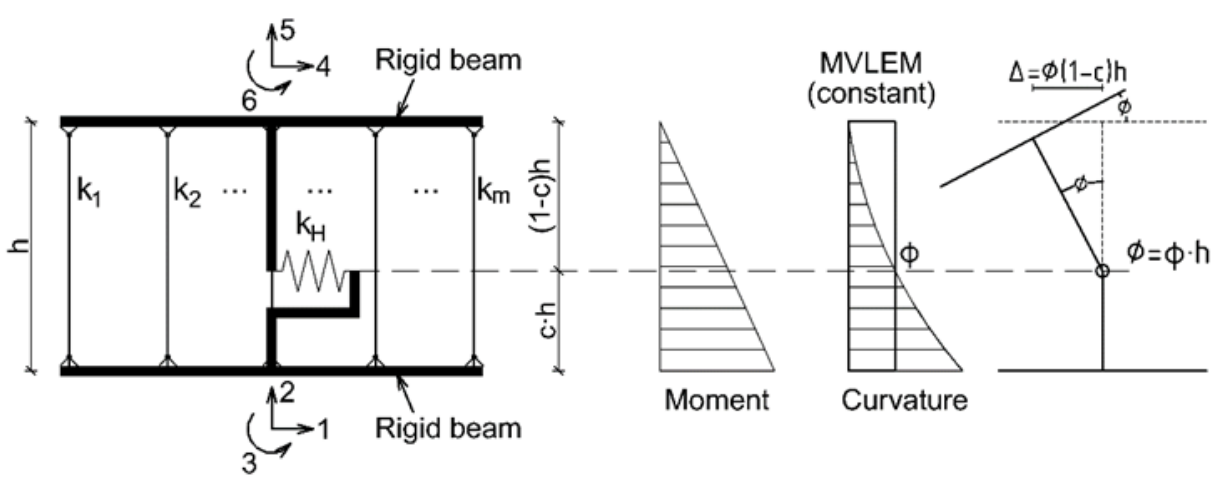

Figure 16. MVLEM element: model, moment, curvature, rotation, and displacements.

Another relevant parameter of the model is the wall discretization in elevation with MVLEM elements. In this model, the wall was discretized in elevation like a stack of MVLEMs one on each other and longitudinally as a series of uniaxial elements along the length of the wall. These uniaxial elements allow taking into account the loading history to which they are subjected, considering the interaction between concrete and reinforcing steel in each of them. With this model, a quasi-static non-linear analysis was developed. The used parameters to fit the numerical response of the model to experimental results of tested walls in this investigation are shown in Table 6. The discretization in elevation and along the transverse section of walls are shown in Figures 17 and 18.

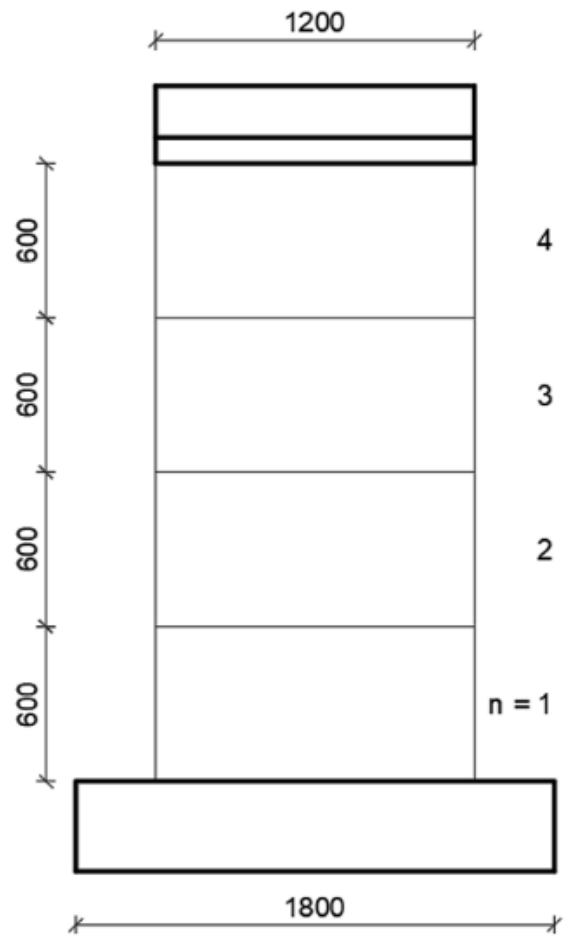

a)

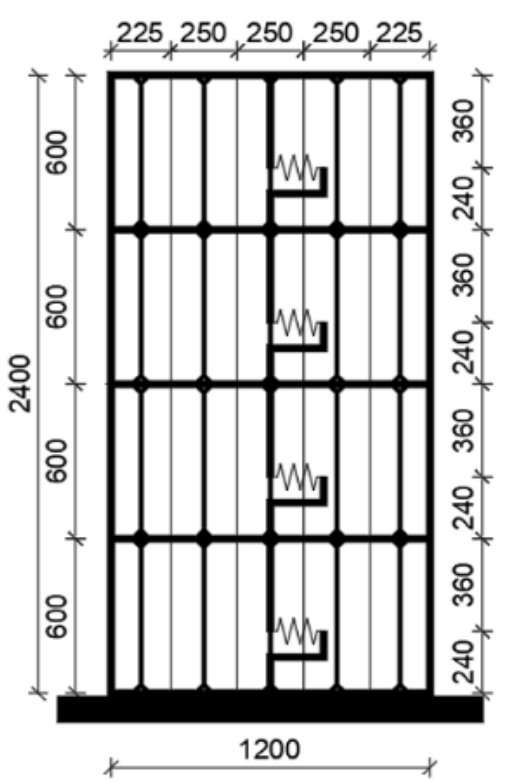

b)

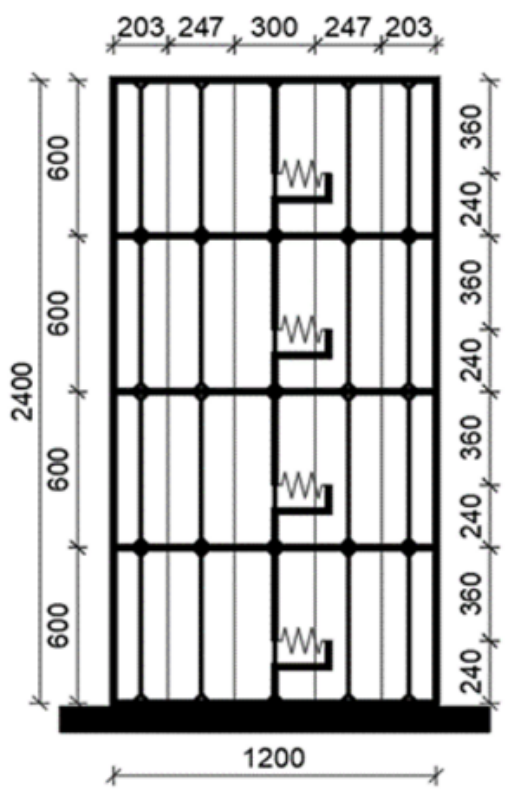

Figure 17. Discretization in elevation of walls: a) MOR10; and b) M1R10. 
Table 6 Parameters for concrete and reinforcing steel for walls MOR10 and M1R10

\begin{tabular}{|c|c|c|c|c|}
\hline \multicolumn{3}{|c|}{ Concrete parameters } & \multirow{2}{*}{$\frac{\text { MOR10 }}{24.70}$} & \multirow{2}{*}{$\frac{\text { M1R10 }}{24.70}$} \\
\hline Compressive strength of the concrete (MPa) & & $f_{c}^{\prime}$ & & \\
\hline Strain in maximum stress & & $\varepsilon_{c}^{\prime}$ & -0.0022 & -0.0022 \\
\hline Elasticity modulus (MPa) & & $E_{c}$ & 19382 & 19382 \\
\hline Critical strain in compression envelope & & $\varepsilon_{c r}^{-}$ & 0.5 & 0.4 \\
\hline Shape parameter for compression & & $r_{c}$ & 3.0 & 3.0 \\
\hline Tension strength & & $f_{t}$ & 0.5 & 0.5 \\
\hline Critical strain in tension envelope & & $\varepsilon_{c r}^{+}$ & 10000 & 10000 \\
\hline Shape parameter for tension & & $r_{t}$ & 1.0 & 1.0 \\
\hline \multicolumn{2}{|l|}{ Reinforcing steel parameters } & $\# 2$ & \#4 & $7 \mathrm{~mm}$ \\
\hline Yield strength (MPa) & $f_{y}$ & 521.1 & 493.0 & 532.7 \\
\hline Maximum strength (MPa) & $f_{u}$ & 674.7 & 650.0 & 596.0 \\
\hline Ultimate strength (MPa) & $f_{r}$ & 586.7 & 577.1 & 500.1 \\
\hline Hardening Strain & $\varepsilon_{\text {sh }}$ & 0.0113 & 0.0150 & 0.003 \\
\hline Ultimate strain & $\varepsilon_{u}$ & 0.0921 & 0.1196 & 0.0300 \\
\hline Pinching factor for strain & pinch $x$ & 0.00 & 0.00 & 0.00 \\
\hline Pinching factor for stress & pinchy & 0.00 & 0.00 & 0.00 \\
\hline Damage due to ductility & damage1 & 0.06 & 0.06 & 0.06 \\
\hline Damage due to energy & damage2 & 0.06 & 0.06 & 0.06 \\
\hline Exponent for stiffness degradation on the unloading based on ductility & Beta & 0.05 & 0.05 & 0.05 \\
\hline
\end{tabular}
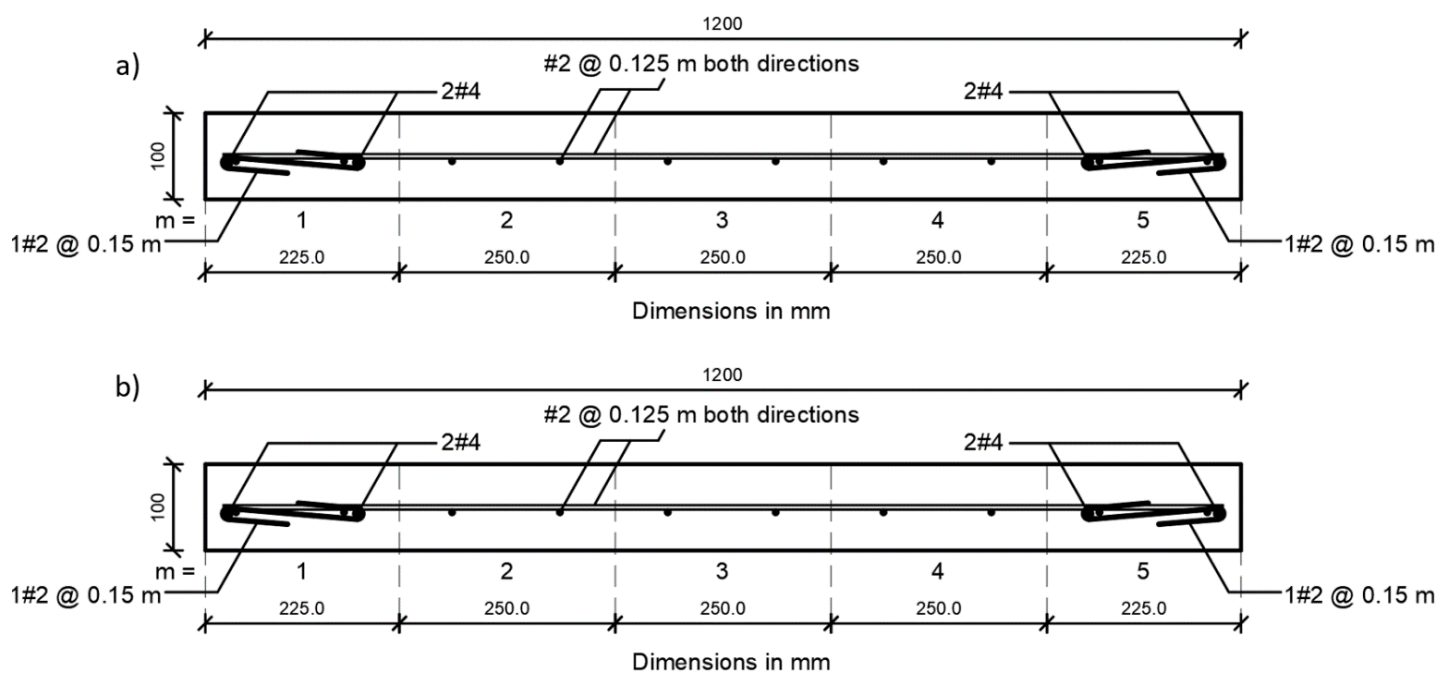

Figure 18. Discretization of transverse section of walls: a) MOR10; and b) M1R10.

\subsection{Results}

The calibration and evaluation of the proposed numerical model (Naranjo, 2018) were carried out by using the response of the monotonic test of wall MOR10, and mainly with the results of the cyclic lateral load test of M1R10 wall and eight other cyclic tests of walls with similar characteristics to those commonly used in Colombia. Variables such as thickness (less than $150 \mathrm{~mm}$ ), aspect ratio, axial load ratio, shear-span ratio, and type of test were considered to select the experimental responses of other walls that could improve the model fitting. The selected test walls were walls W1 and W2, tested by Alarcón et al. (2014), walls R1 and R2, tested by Oesterle et al. (1979), walls RW1 and RW2, tested by Thomsen \& Wallace (1995), and walls MSW2 and MSW3, tested by Salonikios et al. (2000).

Figure 19a shows the correlation between the numerical envelope and force-displacement curve obtained from the monotonic test of wall MOR10, projecting the negative part of the curve. Figure 19b obeys the projection made for the hysterical behavior of this wall once the numerical model was fitted. Despite the difference near the yield point, it is observed that the curves have similar behavior. The maximum experimental strength was $114.7 \mathrm{kN}$, and that calculated by the model was $108.1 \mathrm{kN}$, which is a variation of $5.8 \%$. Figure 20 shows the correlation between the experimental hysteretic behavior of wall M1R10 and the numerical response. The lateral stiffness of the model in the first cycles, for 
drifts lower than $0.5 \%$, is greater than the experimental response, as seen in Figure 20c; however, starting at that level of drift, a good fit with the test response is observed. The maximum experimental shear force was $151.7 \mathrm{kN}$, and the maximum numerical shear force was $140.8 \mathrm{kN}$, which is a variation of $7.2 \%$. Regarding the dissipated energy, there was a greater difference seen between the numerical results and the test. The model reported higher energy dissipation and equivalent viscous damping values, mainly for displacement cycles after the yield point of the wall. In general, the results obtained show that the numerical model can capture the strength and displacement capacity of the walls. Table 7 summarizes the results of the comparison between the experimental and numerical responses obtained with the model.
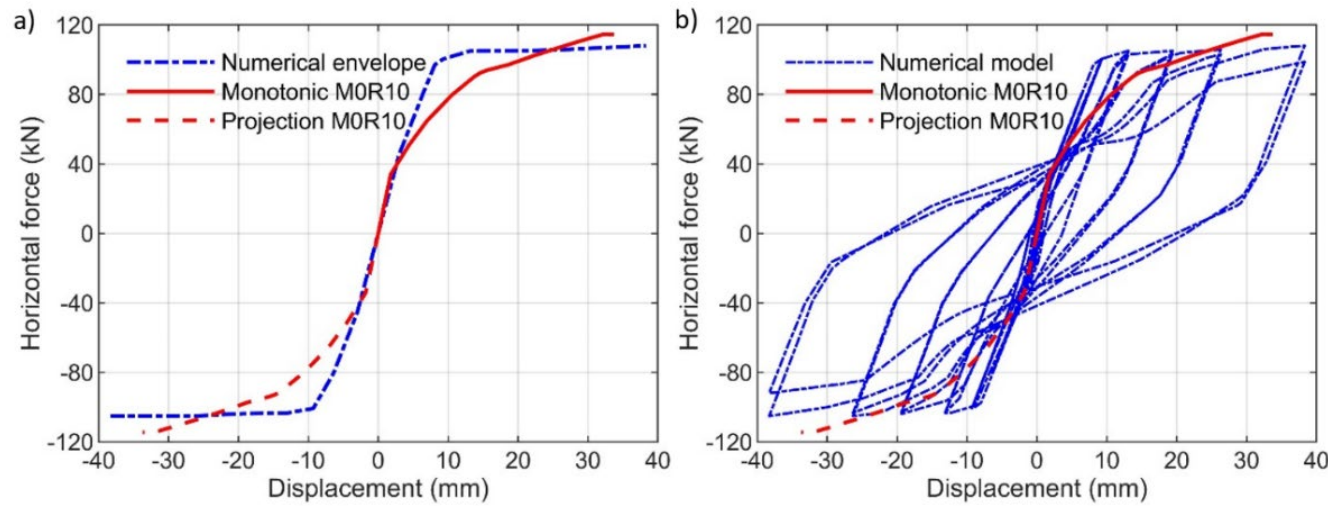

Figure 19. Comparison of the experimental and numerical response of wall MOR10: a) force-displacement vs. numerical envelope response; and b) force-displacement vs. numerical hysteretic response.
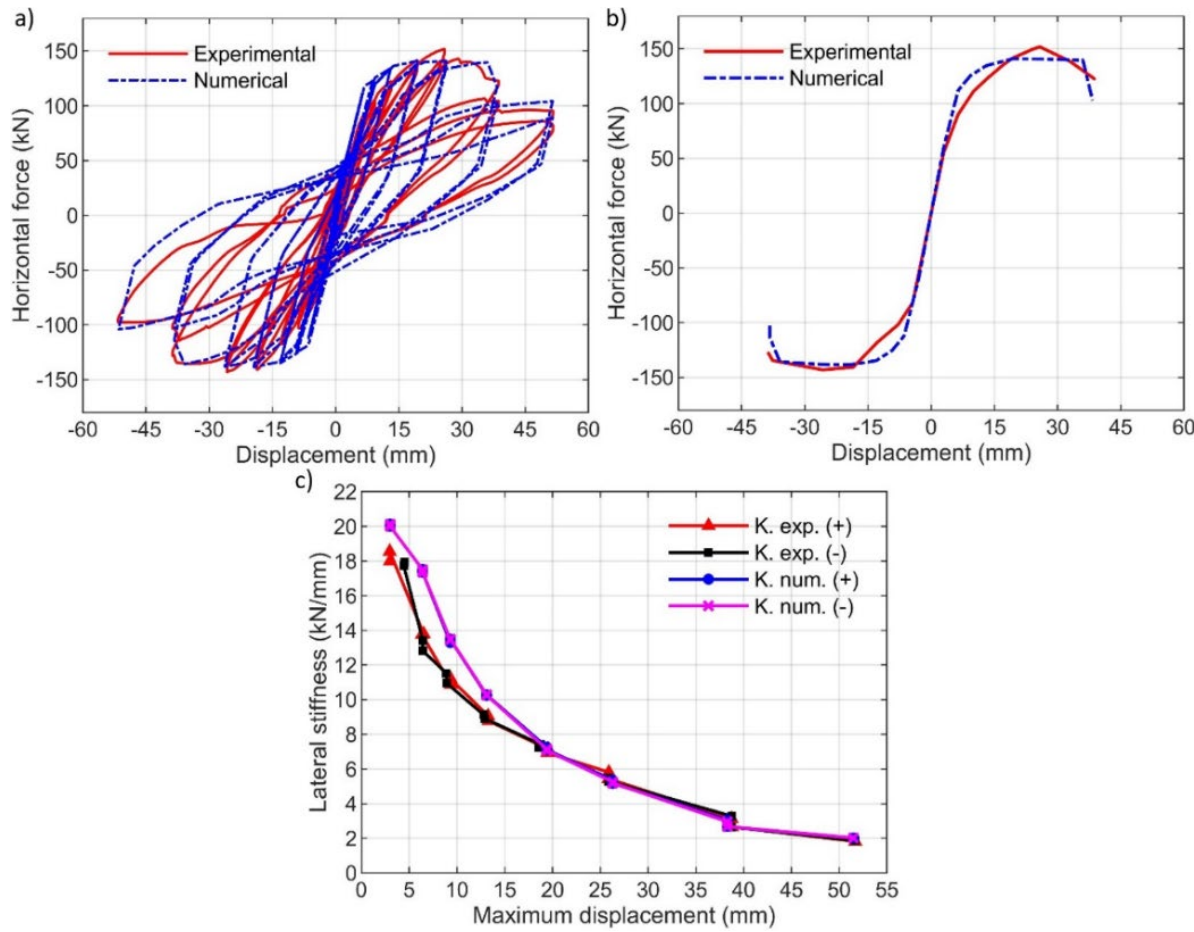

Figure 20. Comparison of the experimental and numerical response of wall M1R10: a) force-displacement relationship; b) force envelope-displacement relationship; and c) stiffness degradation.

Table 7 Comparison of the numerical and experimental response for the MOR10 and M1R10 walls.

\begin{tabular}{ccccccc}
\hline & Experimental MOR10 & Numerical M0R10 & Difference (\%) & Experimental M1R10 & Numerical M1R10 & Difference (\%) \\
\hline $\mathrm{K}_{0}{ }^{+}(\mathrm{kN} / \mathrm{mm})$ & 19.0 & 15.2 & 20.0 & 18.6 & 20.13 & 8.2 \\
$\Delta_{\mathrm{y}}(\%)$ & 0.69 & 0.36 & 47.8 & 0.59 & 0.33 & 44.1 \\
$\mathrm{~V}_{\mathrm{y}}(\mathrm{kN})$ & 95.0 & 98.7 & 3.9 & 124.6 & 120.6 & 3.2 \\
$\Delta_{\max }(\%)$ & 1.36 & 1.60 & 17.6 & 1.08 & 0.81 & 25.0 \\
$\mathrm{~V}_{\max }(\mathrm{kN})$ & 114.7 & 108.1 & 5.8 & 151.7 & 140.8 & 7.2 \\
$\Delta_{\mathrm{u}}(\%)$ & - & 1.8 & - & 1.61 & 1.6 & 0.6 \\
\hline
\end{tabular}


Figure 21 shows the comparison between the experimental and numerical hysterical responses of the other walls used to calibrate the model. Figure 21 shows a good fit of the experimental results and the obtained with the model, which indicates that this is effective to estimate the response of the thin and slender walls in terms of strength, displacement capacity, and stiffness degradation, and gives acceptable results for the estimation of energy dissipation. However, the model is limited in effectively estimating response at the local level. This due because their approach is phenomenological and not microscopic. The model either does not capture the phenomenon of out-of-plane buckling.
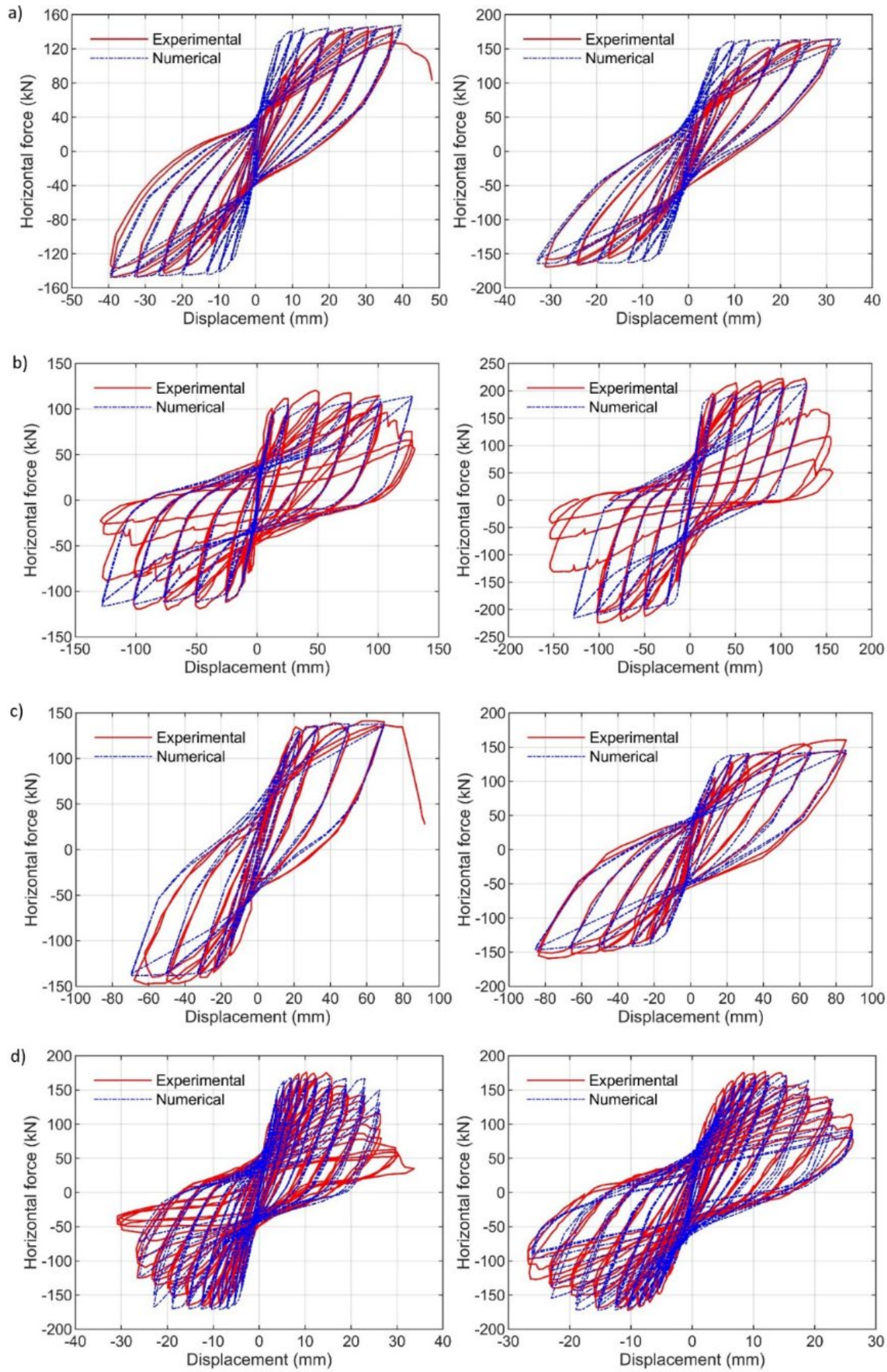

Figure 21. Comparison of the experimental and numerical response of wall: a) W1, W2; b) R1, R2; c) RW1, RW2; and d) MSW2, MSW3. 


\section{CONCLUSIONS}

The seismic performance of two thin and slender reinforced concrete walls, representative of the characteristics commonly used in thin wall buildings in Colombia and in some Latin American countries (industrialized system), was evaluated experimentally. The results of these tests, besides the cyclic testing of other walls from well-known bibliographic references, were used to evaluate and fit a numerical model implemented in OpenSees. From the experimental and numerical results, it is possible to infer the following conclusions:

The walls tested showed a moderate deformation capacity, despite their slenderness ratio $\left(h_{w} / t_{w}>16\right)$ and the reinforcement characteristics. The ultimate drift was of the order of 1.6\%, slightly higher than the NSR-10 limit of $1.43 \%$ for design with cracked sections. This deformation capacity is due to the fact that these are short walls and with low axial load level (ALR $<10 \%)$ since the experimental results of other RCTW indicate that the walls of greater length or with a higher level of axial load generally present reduced deformation capacities, even below $1 \%$. Despite reaching this drift capacity, the level of damage and the stiffness degradation were severe. The Park-Ang damage index of wall M1R10 for a lateral drift of $1 \%$ (the limit per NSR-10 for uncracked sections) was $56 \%$, equivalent to a severe damage level and a nonrepairable state; for the ultimate drift (1.61\%), the index value was $105 \%$, which corresponds to a collapse damage level and a total loss state.

The behavior observed during the tests indicates that from a drift of $0.6 \%$, the level of damage starts to increase considerably. Once the wall M1R10 reached a drift of $1 \%$, the concrete crushing started, and the wall lost $67 \%$ of its lateral stiffness. For a drift of $1.43 \%$, the wall was close to fracture of the web reinforcement, and the stiffness loss was $78 \%$. The stiffness degradation of wall MOR10 was greater in the monotonic test. For a drift of $1 \%$, the initial stiffness decreased by $77 \%$, and when a drift of $1.4 \%$ was reached, the wall had lost $82 \%$ of its stiffness. These experimental responses match those in other studies (Almeida et al., 2014), (Blandon et al., 2018). Although the walls tested are short, and these do not control the overall response of a building (Blandón \& Bonett, 2020), it is possible to indicate, based on the performance and damage observed in the tests, and the experimental databases of RCTW, that a design drift limit as large as $1 \%$, is not recommended. It suggests that the design practices used for this structural system could be insufficient in a high seismic hazard zone.

The results of the numerical simulation showed a good correlation with the experimental results in terms of displacement capacity and strength. Therefore, the calibrated MVLEM model could be used to represent the hysteretic behavior of thin and slender reinforced concrete walls that are representative of this structural system in Colombia. The implementation of this model is relatively simpler than that of other models with a microscopic approach or concentrated plasticity, and this model has a lower computational cost. The MVLEM model calibration process results easier for slender walls $\left(h_{w} / l_{w}>2.5\right)$, than for those of moderate slenderness $\left(1.5<h_{w} / l_{w}<2.5\right)$. This could be attributed to the difficulty to consider the contribution of shear deformation, in total deformation, with a shear resistance mechanism uncoupled from that of bending. Similarly, walls with axial load ratios greater than 0.20 present greater difficulty in their calibration than those with less axial load due to the high impact that axial load has on the wall response and its effect on shear capacity.

\section{ACKNOWLEDGEMENTS}

This work is part of the research project: Evaluation of the seismic performance of buildings of thin structural walls of reinforced concrete, code 110674558634, CT 015-2017. The authors would like to express their gratitude to the Universidad del Valle and the Ministerio de Ciencia Tecnología e Innovación (Minciencias), entities that finance the project.

Author's contributions: All authors contributed to this research and discussed the results and reviews during all phases of the research paper. All authors have read and accepted the published version of the research paper.

Editor: Marcílio Alves.

\section{References}

ACl Committee 318. (2008). Building Code Requirements for Structural Concrete (ACl 318-08). In American Concrete Institute.

ACl Committee 318. (2014). Building Code Requirements for Structural Concrete (ACl 318-14) and Commentary (ACl 318R-14). In $\mathrm{ACl}$ 318-14. American Concrete Institute. 
AIS. (2010). Reglamento Colombiano de Construccion Sismo Resistente NSR-10. Asociación Colombiana de Ingeniería Sísmica.

Alarcón, C., Hube, M. A., \& de la Llera, J. C. (2014). Effect of axial loads in the seismic behavior of reinforced concrete walls with unconfined wall boundaries. Engineering Structures, 73, 13-23.

Almeida, J., Rosso, A., Beyer, K., \& Sritharan, S. (2014). New experimental findings on the stability of thin reinforced concrete walls. 5as Jornadas Portuguesas de Engenharia de Estruturas, February 2015, 1-14.

Almeida, J., Prodan, O., Rosso, A., \& Beyer, K. (2016). Tests on thin reinforced concrete walls subjected to in-plane and out-ofplane cyclic loading. Earthquake Spectra, 33(1), 323-345.

Arteta, C. A., To, D., \& Moehle, J. (2014). Experimental Response of Boundary Elements of Code-Compliant Reinforced Concrete Shear Walls. 10th U.S. National Conference on Earthquake Engineering.

Blandon, C. A., Arteta, C. A., Bonett, R. L., Carrillo, J., Beyer, K., \& Almeida, J. P. (2018). Response of thin lightly-reinforced concrete walls under cyclic loading. Engineering Structures, 176(July), 175-187.

Blandón, C. A., Rave, J. F., \& Bonett, R. L. (2015). Comportamiento de muros delgados de concreto reforzado ante cargas laterales. VII Congreso Nacional de Ingeniería Sísmica, February, 1-10.

Blandón, C., \& Bonett, R. (2020). Thin slender concrete rectangular walls in moderate seismic regions with a single reinforcement layer. Journal of Building Engineering, 28.

Carrillo, J., \& Alcocer, S. M. (2012). Seismic performance of concrete walls for housing subjected to shaking table excitations. Engineering Structures, 41, 98-107.

Carrillo, J., Diaz, C., \& Arteta, C. A. (2019). Tensile mechanical properties of the electro-welded wire meshes available in Bogotá Colombia. Construction and Building Materials, 195, 352-362.

Comisión-Asesora-Permanente-para-el-Régimen-de-Construcciones-Sismo-Resistentes. (2017). Resolución número 0017 del 04 de diciembre de 2017.

Dazio, A., Beyer, K., \& Bachmann, H. (2009). Quasi-static cyclic tests and plastic hinge analysis of RC structural walls. Engineering Structures, 31, 1556-1571.

Diaz, S. A., Pujades, L. G., Barbat, A. H., Vargas, Y. F., \& Hidalgo-Leiva, D. A. (2017). Energy damage index based on capacity and response spectra. Engineering Structures, 152, 424-436.

Elmenshawi, A., \& Brown, T. (2010). Hysteretic energy and damping capacity of flexural elements constructed with different concrete strengths. Engineering Structures, 32, 297-305.

Gonzales, H., \& López-Almansa, F. (2012). Seismic performance of buildings with thin RC bearing walls. Engineering Structures, 34, 244-258.

Hube, M. A., Marihuén, A., Llera, J. C. De, \& Stojadinovic, B. (2014). Seismic behavior of slender reinforced concrete walls. Engineering Structures, 80, 377-388.

Kolozvari, K., \& Wallace, J. W. (2016). Practical Nonlinear Modeling of Reinforced Concrete Structural Walls. Journal of Structural Engineering.

Looi, D. T. W., Su, R. K. L., Cheng, B., \& Tsang, H. H. (2017). Effects of axial load on seismic performance of reinforced concrete walls with short shear span. Engineering Structures.

Mander, J. B., Priestley, M. J. N., \& Park, R. (1988). Theoretical Stress-Strain Model for Confined Concrete. Journal of Structural Engineering.

Mazzoni, S., McKenna, F., Scott, M. H., \& Fenves, G. L. (2009). Open System for Earthquake Engineering Simulation User Command-Language Manualle. Pacific Earthquake Engineering Research Center. University of California, Berkeley.

Naranjo, C. (2018). Respuesta histerética de muros delgados de concreto reforzado, M.Sc. Thesis (in Spanish). Universidad del Valle.

Oesterle R.G, Aristizabal-Ochoa J.D, Fiorato A.E, Russell H.G, \& Corley W.G. (1979). Earthquake resistant structural walls - Tests of isolated walls Phase II.

Orakcal, K., Wallace, J. W., \& Conte, J. P. (2004). Flexural Modeling of Reinforced Concrete Walls- Model Attributes. ACI Structural Journal, 101, No. 5, 688-698. 
Ortega, R., Torres, P., Cuesvas, E., Cruz, A., Marulanda, J., \& Thomson, P. (2019). Análisis Estadístico de Edificaciones de Muros Delgados de Concreto Reforzado en Zona de Amenaza Sísmica Alta : Casos Cali y Popayán. IX Congreso Nacional de Ingeniería Sísmica, 1443-1458.

Park, Y. J., Ang, A. H. S., \& Wen, Y. K. (1984). Seismic damage analysis and damage-limiting design of R.C buildings. In Civil Engineering Studies, Structural Research Series.

Park, Y. J., Reinhorn, A. M., \& Kunnath, S. K. (1987). IDARC: Inelastic damage analysis of reinforced concrete frame - shear-wall structures. In Technical Report NCEER-87-0008, National Center for Earthquake Engineering Reasearch, State University of New York at Buffalo.

Parra, P. F., \& Moehle, J. P. (2017). Stability of Slender Wall Boundaries Subjected to Earthquake Loading. ACI Structural Journal, 114 (6), 1627-1636.

Parra, P. F., \& Moehle, J. P. (2014). Lateral Buckling in Reinforced. 10th National Conference on Earthquake Engineering, December.

Paulay, T., \& Priestley, M. J. N. (1993). Stability of ductile structural walls. ACl Structural Journal, 90, 385-392.

Quiroz, L. G., Maruyama, Y., \& Zavala, C. (2013). Cyclic behavior of thin RC Peruvian shear walls: Full-scale experimental investigation and numerical simulation. Engineering Structures, 52, 153-167.

Rosso, A., Almeida, J. P., \& Beyer, K. (2016). Stability of thin reinforced concrete walls under cyclic loads: state-of-the-art and new experimental findings. Bulletin of Earthquake Engineering, 14, 455-484.

Rosso, A., Jiménez-Roa, L. A., De Almeida, J. P., Zuniga, A. P. G., Blandón, C. A., Bonett, R. L., \& Beyer, K. (2018). Cyclic tensilecompressive tests on thin concrete boundary elements with a single layer of reinforcement prone to out-of-plane instability. Bulletin of Earthquake Engineering, 16(2), 859-887.

Salonikios, T. N., Tegos, I. A., Penelis, G. G., \& Kappos, A. J. (2000). Cyclic Load Behavior of Low-Slenderness Reinforced Concrete Walls: Failure Modes, Strength and Deformation Analysis, and Design Implications. ACl Structural Journal, 97(1), 132-141.

Scott, M. H., \& Filippou, F. C. (2016). Hysteretic Material - OpenSeesWiki. Retrieved from http://opensees.berkeley.edu wiki/index.php Hysteretic_Material.

Takahashi, S., Yoshida, K., Ichinose, T., Sanada, Y., Matsumoto, K., Fukuyama, H., \& Suwada, H. (2013). Flexural drift capacity of reinforced concrete wall with limited confinement. ACl Structural Journal, 110 (1), 95.

Thomsen IV, J. H., \& Wallace, J. W. (1995). Displacement-based design of reinforced concrete structural walls: Experimental studies of walls with rectangular and T-shaped cross sections.

Usta, M., Pujol, S., ACI Subcommittee 445B, Puranam, A., Song, C., \& Wang, Y. (2017). ACl 445B Shear Wall Database. https://purr.purdue.edu/publications/2434/1

Vulcano, A., Bertero, V. V, \& Colotti, V. (1988). Analytical modeling of R/C structural walls. Proceedings of the 9th World Conference on Earthquake Engineering, 2-9 August.

Wallace, J. W., Arteta, C., \& Moehle, J. (2016). Deformation capacity of thin reinforced concrete shear walls. 016 New Zealand Society for Earthquake Engineering (NZSEE) Annual Technical Conference, April.

Wallace, J. W., Massone, L. M., Bonelli, P., Dragovich, J., Lagos, R., Lüders, C., \& Moehle, J. (2012). Damage and implications for seismic design of RC structural wall buildings. Earthquake Spectra, 28 (S1), S281-S299. 